\title{
A REVISION OF THE SARATHROGAMMARUS-GROUP (CRUSTACEA, AMPHIPODA)
}

\author{
by \\ JAN H. STOCK \\ Institute of Taxonomic Zoology, University of Amsterdam, The Netherlands
}

\begin{abstract}
The Sarathrogammarus-group consists of the genera Sarathrogammarus (7 species, of which 1 new), Neogammarus (2 species, of which 1 new), Comatogammarus (new genus, with 1 species), Rhipidogammarus (new genus, with 2 species, of which 1 new), and Longigammarus (1 species). Keys to genera and species are provided.
\end{abstract}

\section{INTRODUCTION}

This article is the third in a series of revisions of species or genus groups within what was considered Gammarus s.l. in the past. The previously published revisions concerned the Gammarus locusta-group (Stock, 1967) and the Echinogammarus pungens-group (Stock, 1968).

The present paper treats a group of species related to "Gammarus" rhipidiophorus Catta, 1878. The morphological differentiation within this group is wider than usual, and starting 1935 three distinct genera or subgenera, Sarathrogammarus, Neogammarus, and Longigammarus, have been proposed for the reception of the species belonging to the group. Two more genera will be added here on the basis of the results of my revision, whereas three new species will be described.

The members of the Sarathrogammarus-group are often considered relics of the Tethys fauna, since they are distributed from the Azores and Madeira, along the Mediterranean coasts, to Afghanistan, and since the greater part of the species prefers mixohaline to limnic habitats, with only two marine representatives left. The distributional data on these relatively rare gammarids are so scarce, however, that the Tethys theory, attractive as it may seem, is hardly supported by any factual evidence.

\section{ACKNOWLEDGEMENTS}

Material used in this study was received from the following persons and/or institutes, the kind assistance of which is gratefully acknowledged: Dr. J. Forest, Muséum National d'Histoire Naturelle, Paris, France (MNHN); Dr. G. S. Karaman, Titograd, Yugoslavia; Dr. C. M. Naumann, Zoological Institute, University of Kabul, Afghanistan; Dr. S. Ruffo, Museo Civico di Storia Naturale, Verona, Italy (MCV); Dr. B. Sjöstrand, Zoological Institute, University of Lund, Sweden (ZIL). The remaining material comes from the collections of the Zoölogisch Museum Amsterdam (ZMA).

\section{THE SARATHROGAMMARUS-GROUP}

A number of Eurasian Gammaridae are characterized by a shortened endopod in the third uropod (whose length is much less than half the length of the first exopod segment), in combination with two other characters: simple gills and a non-projecting basis in the seventh leg. These genera can be arranged into three groups, viz. the Sarathrogammarus-group, the Echinogammarus-Chaetogammarus-group, and the Eulimnogammarusgroup, the iatter comprising - but for a small number of very remarkable exceptions, see Pinkster \& Stock, 1970 - only members of the Baikal fauna.

The Sarathrogammarus-group is related to the Echinogammarus-Chaetogammarus-group but the latter is no doubt more generalized in morphology. Special characters, regularly - though usually not all at a time - found in the Sarathrogammarus-group are:

(1) Feeble sexual dimorphism, chiefly limited to the distal segments of P1, P2, and P3 (in the 
E.- $C h$.-group also in $\mathrm{A} 2, \mathrm{P} 7$, and ur3).

(2) The absence (or in some cases displacement to an unusual position) of the medial palmar spine in P2 (in the E.-Ch.-group usually a well-developed medial palmar spine is found, although numerous exceptions are known).

(3) The tendency towards elongation of the carpus in $\mathrm{P} 2$, which becomes trapezoidal or even linear and carries a higher number of transverse rows of elements on its posterior margin than the propodus (in the E.-Ch.group the carpus is triangular and carries fewer rows of elements than the propodus).

(4) The tendency towards reductions in size and armature of uropod 1, and of apical exopod segment and endopod of uropod 3 (both uropods normally developed in the E.-Ch.group).

(5) The tendency towards loss of the calceoli in A2 $\sigma$ (often, though not always, present in the $E$.-Ch.-group).

(6) The tendency towards modifications in P3, and sometimes in $\mathrm{P4}$, at least in the male, but in some species also in the female. These modifications can be described as follows:

(a) Merus with 10 or more transverse rows ("fans") of long setae (in the E.-Ch.-group 3 to 9 groups, but no "fans", of elements).

(b) Carpus with more than 10 transverse rows ("fans") of long setae (less than 6 groups of elements in the E.-Ch.-group).

(c) Propodus with 5 to 8 transverse rows of long setae (less than 5 groups of elements in the E.-Ch.-group).

(d) P3 much more strongly developed than P4 (P3 equal to, or only slightly stronger than, $\mathrm{P} 4$ in the E.-Ch.-group).

(e) Carpus 1.8 to 2.0 times as wide as the propodus (1.0 to 1.4 times in the $E$. . $C h$.-group).

As said before, not all these characters ought to be present in combination in every individual member of the Sarathrogammarus-group. So, the genus Neogammarus in particular tends to bridge the gap between the two groups.

As far as I can judge from the members of the Sarathrogammarus-group that I have studied alive, body pigments are lacking in this group (in preserved state they remain white), while in the Echinogammarus - Chaetogammarus-group, the body usually is pigmented (they turn reddish brown in the preservation fluid).
On the basis of the above set of characters, it seems justified to exclude species not having sufficient morphological agreement to the Sarathrogammarus-group. There are two such species, both originally attributed to the genus (or subgenus) Sarathrogammarus, but which in reality should be placed in or near the genus Chaetogammarus. These species are:

Gammarus (Sarathrogammarus) shadini Birstein, 1948: 266-268, fig. 2, from various localities in Tadzhikistan (U.S.S.R.). and Sarathrogammarus ruffoi G. Karaman, 1971: 199-206, figs. 1-25, from Afghanistan.

It should be noted that both these species have two characters reminiscent of the Sarathrogammarus-group, viz. a small rounded eye, and the absence of medial palmar spines in P1 and P2. As to the shape of the eye, it is clear in my opinion that this feature is related to life in fresh waters. Most "older" European fresh water species 1), irrespective to the genus or group to which they belong, have a rounded eye, only the more recent invaders 2 ) from the sea into fresh waters have conserved an elongated eye shape, common to all marine forms. Within one species-group, one can find taxa with rounded and with elongated eyes, the most classic example of which is Gammarus pulex versus $G$. duebeni, both members of the socalled subgenus Rivulogammarus. In tropical fresh water species, the eyes even have invariably lost pigmentation. It is concluded then, that the shape of the eye is correlated with the shift from life under marine to limnic conditions, and has little or no significance as a generic character.

The same holds true for the presence or absence of a medial palmar spine. It is easy to find sets of closely related species, being no doubt congeneric, in which the one has, the other lacks a medial palmar spine. Such sets are e.g.: Echinogammarus berilloni (Catta, 1878) versus $E$. aquilifer Pinkster, 1969; Chaetogammarus ischnus ssp. sowinskyi (Behning, 1914) versus Ch. i. ischnus (Stebbing, 1906); Eulimnogammarus toletanus Pinkster \& Stock, 1970 versus E. macrocarpus Stock, 1969; Sarathrogammarus trichiatus n.sp. versus S. afghanus Ruffo, 1958.

Concluding, I think that neither the shape of the eye, nor the presence or absence of a medial pal-

1) E.g., the Gammarus pulex-group, G. fossarum, Eulimnogammarus div. spec., the Echinogammarus simonigroup.

2) E.g., Echinogammarus stammeri and Gammarus duebeni. 
mar spine can be used as a taxonomic character on generic level.

On the other hand, the reduction of the first uropod, as seen in certain members of the Sarathrogammarus-group, is a character of sufficient evolutionary significance to be used as diagnostic on the generic level. I agree in this respect with Ruffo, 1937, who has been the first to use the reduction of the first uropod as generic character for his genus Neogammarus. In the light of the discovery of two new species described in this paper, I have felt it justified to split Neogammarus in Ruffo's sense into two genera, Neogammarus s.str. and Rhipidogammarus n.gen. Dahl, 1958, came - on other grounds - also to the conclusion that the species attributed originally to Neogammarus should be divided over two genera.

Finally, a new genus is proposed for Sarathrogammarus ferghanensis Martynov \& Behning, 1948, from Tadzhikistan and Afghanistan, chiefly on basis of making the proposed re-arrangement on generic level more balanced and of making the genera easy to diagnose.

\section{REMARKS ON THE MOUTH PARTS AS TAXONOMIC CHARACTERS}

In most gammarids, the mouth parts are rather uniform, resembling those figured by Sexton \& Spooner, 1940, fig. 9, for Chaetogammarus pirloti (Sexton \& Spooner). Of course important exceptions are found in the structure of the mandible palp that often offers diagnostic features on the species level, and sometimes in the first maxilla.

Of the Sarathrogammarus-group, the genus Longigammarus is chiefly characterized by aberrant mouth parts ( $\mathrm{mx} 1, \mathrm{mx} 2, \mathrm{mxp}$ ). The other members of the group are fairly uniform again (the "Chaetogammarus pirloti type" of mouth parts), although in finer details, such as the ornamentation of the elements on the various buccal appendages, differences can be found.

In fig. 1, a number of such differences are illustrated. Figs. $1 \mathrm{a}$ and $1 \mathrm{c}$ show the aberrant (widened) shape of the lobes of $m \times 2$ and $m \times p$ in Longigammarus, as compared with the "normal" shape found in the other members of the Sarathrogammarus-group (depicted is, as an example, Neogammarus festae, figs. 1b, 1d). Whereas Longigammarus bears setiform elements only on the inner margin of the outer lobe of its maxilli- ped (fig. 1a, detail), the other genera bear setiform plus spiniform elements in that place. The shape of these spiniform elements might change from pectinate (in Rhipidogammarus and Sarathrogammarus, see fig. 1e) to almost smooth (in Neogammarus, see figs. $1 \mathrm{~b}$ and $1 \mathrm{f})$.

On the outer lobe of the first maxilla, long, robust spines ("teeth") occur, which bear median denticulations. These denticulations are numerous (12-28) on all teeth in Longigammarus (fig. 10), less numerous in the other members of the group. In these members, the outer teeth bear four to none denticulations, the inner teeth bear 6 to 11 denticulations (figs. $1 \mathrm{~g}, \mathrm{~h}, \mathrm{i}, \mathrm{j}, \mathrm{k}, \mathrm{l}, \mathrm{m}, \mathrm{n}$ ). The number of denticulations can vary widely, however, within one species, and should be used with great care as a taxonomic character.

\section{SYNOPSIS TO THE GENERA}

The salient differences between the genera of the Sarathrogammarus-, the Echinogammarus-, Chaetogammarus-, and the Eulimnogammarus-groups are shown in table I. In a very condensed way, these genera can also be identified with the following key (based on males only):

la) Propodus P2 $>\mathrm{P} 1$. . . . . . . . . . 2

b) Propodus P2 $<$ P1 . . Eulimnogammarus

2a) Uropod 1 reduced . . . . . . . . . . 3

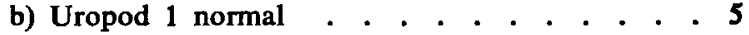

3a) P3 unmodified. Dorsum of urosome unarmed. Neogammarus

b) P3 modified. Dorsum of urosome spiniferous . . 4

4a) Mouth parts modified. Longigammarus

b) Mouth parts unmodified. Rhipidogammarus

5a) P3 unmodified. Uropod 3 normal.

Echinogammarus and Chaetogammarus

b) P3 modified. Uropod 3 with reductions . . . 6 6a) P4 modified Comatogammarus

b) P4 unmodified Sarathrogammarus

\section{TAXONOMIC PART}

\section{Neogammarus Ruffo, 1937}

Gammarus (Neogammarus) Ruffo, 1937: 442; Dahl, 1958: $15-17$.

Neogammarus. - G. Karaman, 21969b: 34; G. Karaman, 1971: 206.

Diagnosis. - Gammaridae, Sarathrogammarusgroup. Eyes pigmented (large and elongated in the two species known). Dorsal surface of urosome unarmed. A2 $\sigma^{*}$ with calceoli. Carpus P2 $\sigma^{\pi}$ un- 


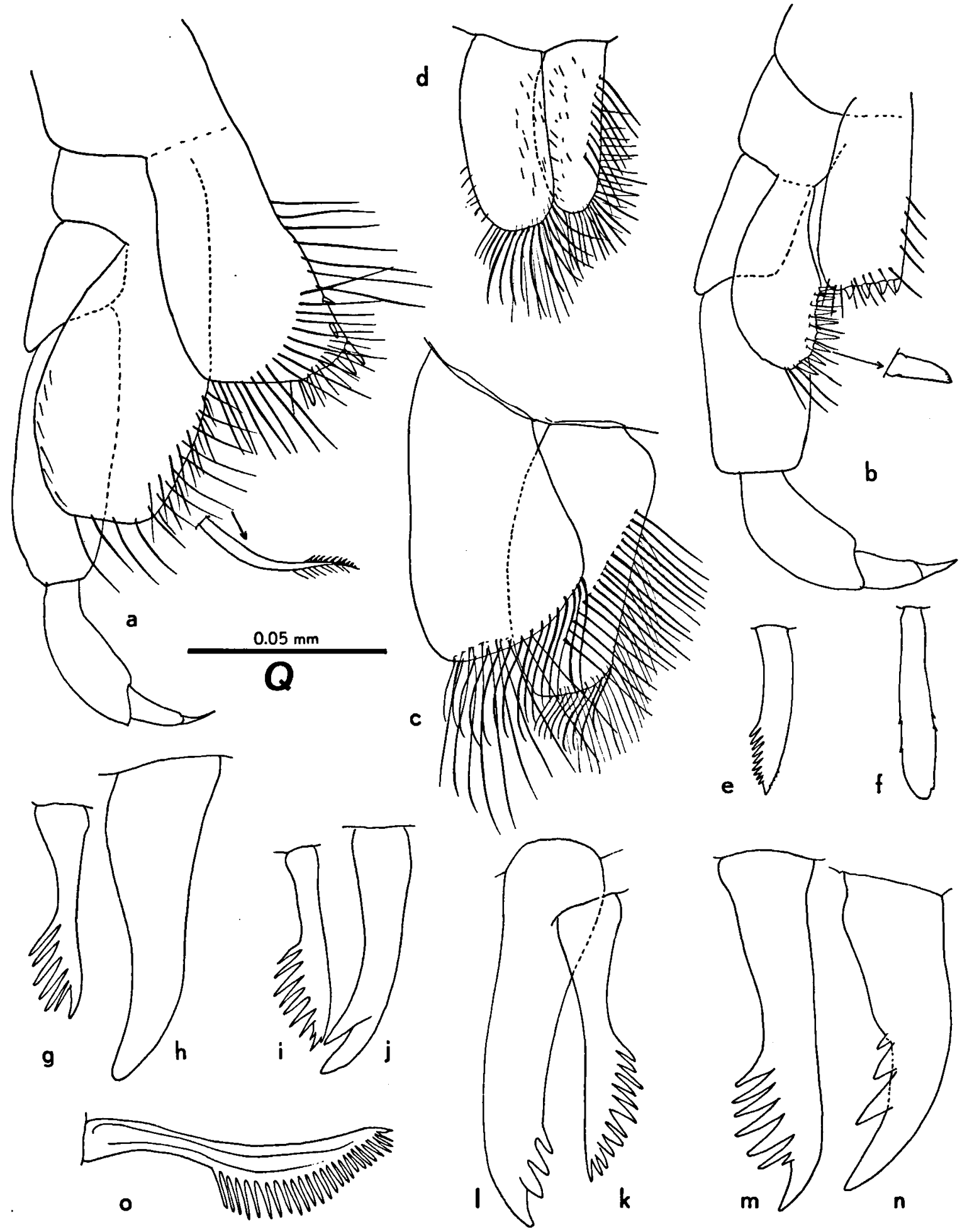

Fig. 1. Mouth parts of various members of the Sarathrogammarus-group. a, maxilliped of Longigammarus bruni (G. Karaman), 9 (scale B); b, maxilliped of Neogammarus festae (Ruffo), of (B); c, second maxilla of Longigammarus bruni, $\%$ (B); d, second maxilla of Neogammarus festae, $\hat{\delta}$ (B); e, spine from medial margin of outer lobe of maxilliped in Rhipidogammarus karamani n. sp., $\hat{o}$ (Q); f, same in Neogammarus nudus n. sp., $\delta$ $(\mathrm{Q}) ; \mathrm{g}, \mathrm{h}$, inner and outer spine, respectively, of outer lobe of first maxilla in Sarathrogammarus guernei (Chevreux), $(Q)$; $i, j$, same in Sarathrogammarus madeirensis (Dahl), of (Q); k, l, same in Rhipidogammarus karamani, ô (Q); $\mathrm{m}, \mathrm{n}$, same in Neogammarus festae, of (Q); $o$, distal spine from outer lobe of first maxilla in Longigammarus bruni, $\$(\mathrm{Q})$. Fine ornamentation of the elements omitted in $\mathrm{a}-\mathrm{d}$; all armature omitted from the palp in $a$ and $b$. 
Table I. Salient differences between certain gammarid genera with short endopod in uropod $3(+=$ character available in the genus; $-=$ character absent; $\pm=$ genus contains species with or without the character).

1. Mouth parts ( $\delta$ ) modified (lobes of $m \times 2$, especially the outer one, widened; all spines on outer lobe of $\mathrm{mxl}$ with $20-30$ unilateral teeth; inner lobe of mxp widened; outer lobe of $\mathrm{mxp}$ with setiform elements only)

2. A2 of with calceoli

3. Propodus P2 (ô $q$ ) smaller than that of $\mathbf{P 1}$

4. Carpus P2 ô modified (trapezoidal to elongately trapezoidal, thus not triangular, with more transverse rows of elements than on the propodus)

5. P3 o modified (merus and carpus widened, with more than 10 transverse rows of long setae, propodus with 5-8 rows of long setae)

6. P4 of modified (merus and carpus with more than 10 transverse rows of long setae)

7. P5-P7 if $\&$ modified (distal three segments, in particular the merus, shortened and widened)

8. Dorsal surface of urosome $(\hat{t}+)$ unarmed

9. First uropod reduced ( $\hat{\sigma}$ \&)

10. Second exopod segment of ur3 ( $\delta$ ) reduced

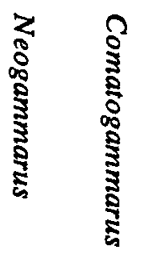

$\underbrace{2}$

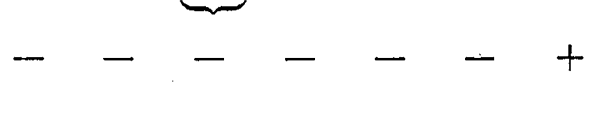

11. Endopod of ur3 ( $\delta \&$ ) scale-like, with reduced arma-

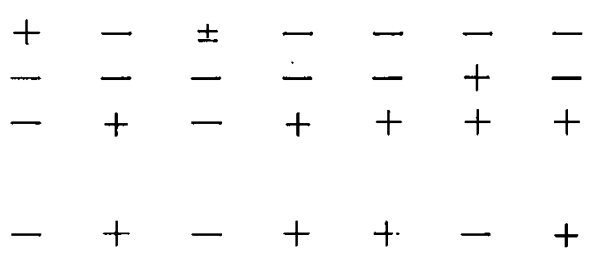
ture

modified (triangular, with little numerous rows of elements). P3 ( $\left.\sigma^{*} \uparrow\right)$ unmodified. P5 to P7 ( $\left.\sigma^{*} \%\right)$ modified (merus, carpus, and propodus, especially the former, widened and shortened). Uropod 1 $\left(\sigma^{\prime} \%\right)$ reduced. Uropod $3\left(\sigma^{\prime} \%\right)$ without reductions.

Type species by subsequent selection (Dahl, 1958): Gammarus (Neogammarus) festae Ruffo, 1937. The later selection (G. Karaman, ?1969: 57; 1971: 206) of Gammarus rhipidiophorus as type species is therefore invalid.

\section{KEY TO THE SPECIES (\& \&)}

1 a) Basis of P7 concave, with a postero-proximal lobe. Basis of P5 without postero-distal lobe.

N. festae (Ruffo, 1937)

b) Basis of P7 with straight, non-projecting posterior margin. Basis of P5 with postero-distal lobe.

N. nudus n. sp.
Neogammarus festae (Ruffo, 1937). Figs. 1 b, d, $\mathrm{m}, \mathrm{n} ; 2 ; 3 ; 4$.

Gammarus (Neogammarus) Festae Ruffo, 1937: 438442, fig. I.

Neogammarus festae. - Barnard, 1958: 63.

Gammarus (Neogammarus) festae. - Dahl, 1958: 15-17; Dahl, 1959: 233.

Material examined. -

France:

- Dép. Bouches-du-Rhône: Carry - le Rouet, Calanque des Sources Salées, under stones on the beach in the place where the affluent of a brackish source mixes with the waves, 24 July 1971, 36 specimens, incl. ovigerous females (ZMA).

Remarks. - Though the present species is amply described by Ruffo, 1937, from Cogoleto, Gulf of Genova, Italy, it was thought wise - in particular 


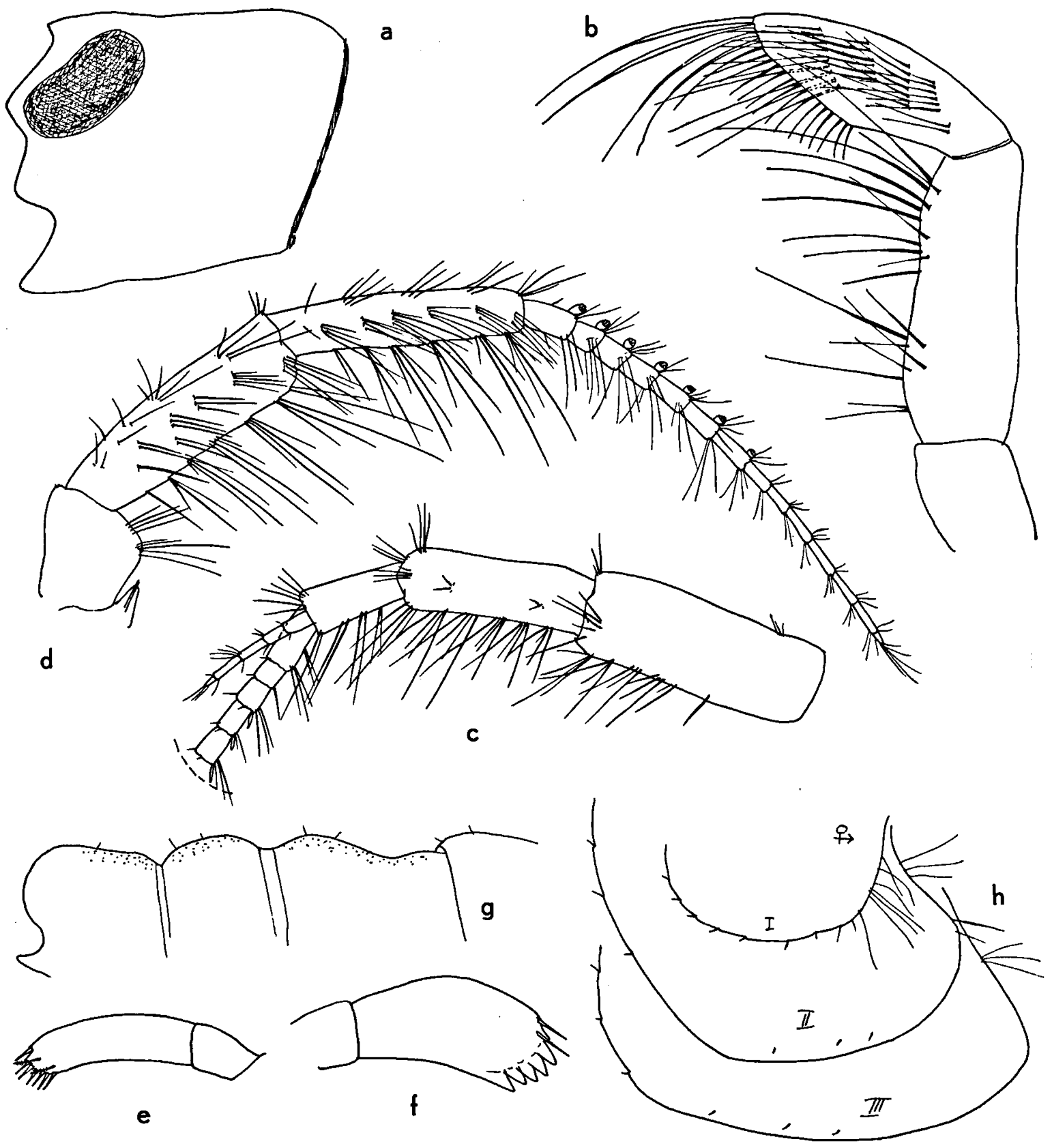

Fig. 2. Neogammarus festae (Ruffo, 1937), $\hat{o}$, from Carry- le Rouet, France, coll. ZMA. a, head from the left (scale A); b, mandible palp, fine ornamentation of the elements omitted (B); c, first antenna, distal segments of 23-segmented flagellum omitted (A); $d$, second antenna (A); e, palp of left first maxilla (B); $f$, palp of right first maxilla (B); $g$, contour of urosome, from the left (A); h, epimeral plates I to III, from the right (C). 

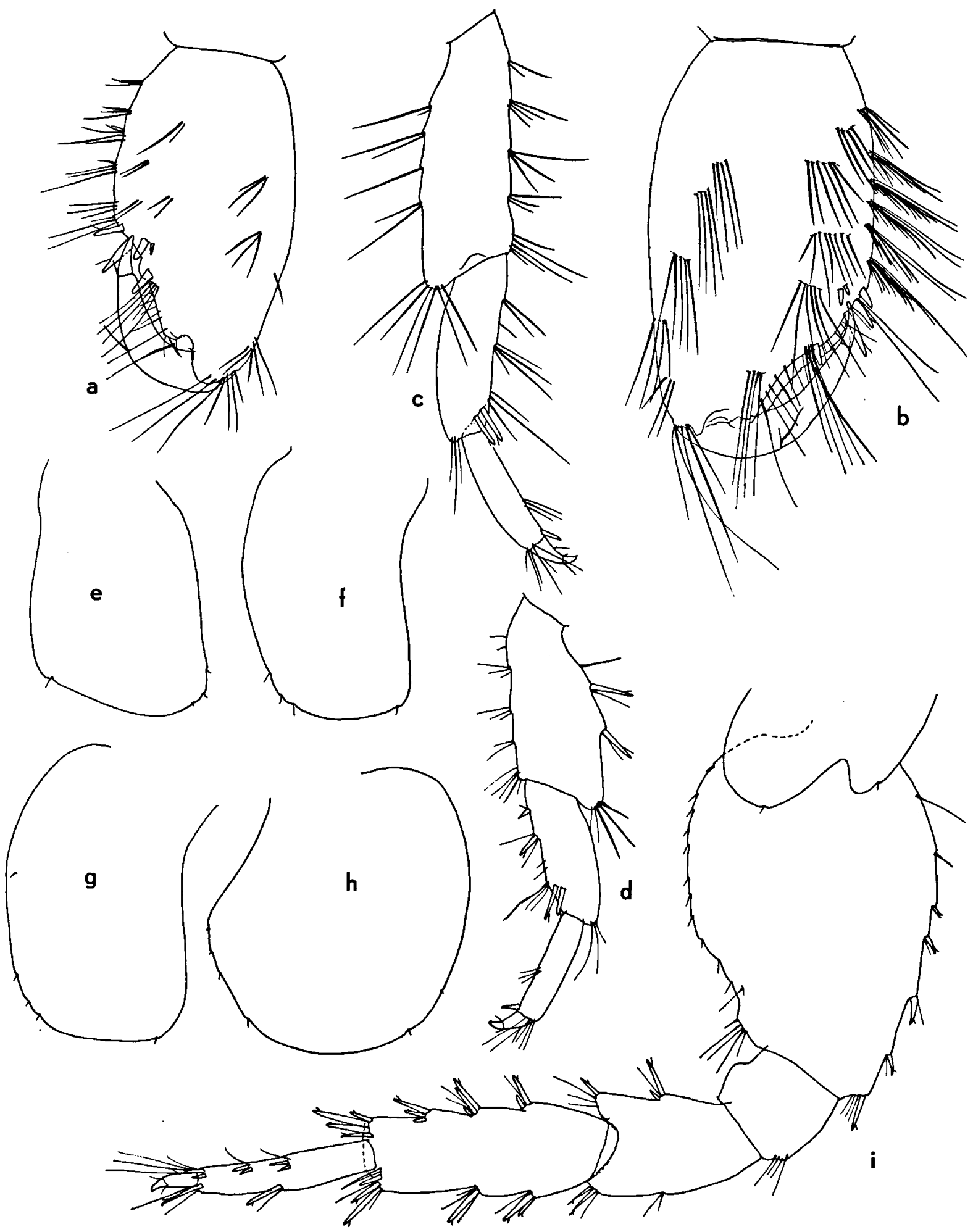

Fig. 3. Neogammarus festae (Ruffo, 1937), $\delta$, from Carry - le Rouet, France, coll. ZMA. a, propodus of leg 1 (scale P); b, propodus of leg 2 (P); c. distal seg-

ments of leg 3 (C); d, distal segments of leg 4 (C); e, first coxal plate (A); $f$, second coxal plate $(A) ; g$, third coxal plate (A); $h$, fourth coxal plate (A); i, fifth leg (C). 

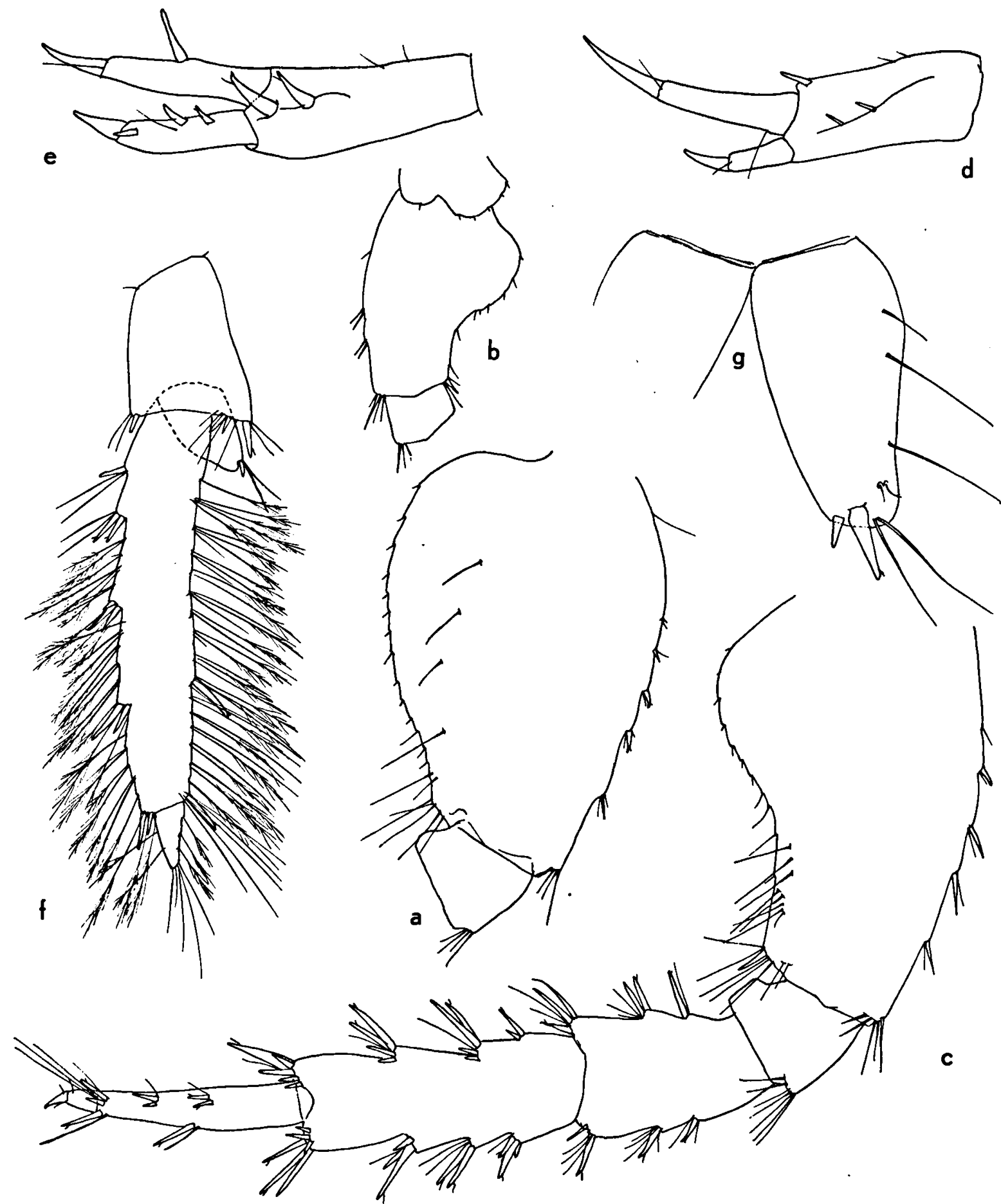

Fig. 4. Neogammarus festae (Ruffo, 1937), from Carry - le Rouet, France, coll. ZMA. a, basis of sixth leg, $\hat{\delta}$ $\hat{o}$ (C); d, first uropod, $\hat{o}$ (C); e, second uropod, $\hat{o}$ (C); (scale C); b, basis of seventh leg, $₹$ (C); c, seventh leg, f, third uropod, of (C); g, telson, of (B). 
in the light of the discovery of the closely related $N$. nudus n.sp. - to insert a completely new set of figures of this species. The freshly collected material comes from a locality on the French Rivièra coast not far from the Italian type locality.

The greatest male in our collection is $91 / 2 \mathrm{~mm}$ long, an ovigerous female has a length of almost $7 \mathrm{~mm}$. The projecting proximo-posterior lobe on the basis of P7 is more strongly developed in female than in male. Otherwise, the female differs chiefly from the male in the much smaller gnathopods 1 and 2, and in the absence of calceoli on the second antennae.

Neogammarus nudus n. sp. Figs. 1f; 5; 6; 7.

Material examined. -

France:

- Dép. Bouches-du-Rhône: Cassis, Plage de Bestouan, exposed beach, amongst cobbles in the surf zone, 5 Jan. 1968, 4 क (including 1 के holotype), 10 क (ZMA Amph. 101.989a-b).

- Dép. Alpes-Maritimes: Bouches-du-Loup, surf zone on beach (cobbles and coarse sand), 25 July 1971, 21 specimens (ZMA); Bouches-du-Loup, mouth of river Loup, where the fresh stream mixes with the seawater, coarse sand and cobbles, 23 July 1971, 7 specimens (ZMA), chlorinity $37 \mathrm{mg} / 1$; Cros-deCagnes, about $50 \mathrm{~m} \mathrm{~W}$. of mouth of river Cagne, in interstices on the shingle beach, just within the reach of the breaking waves (predominant particle size 4 to $14 \mathrm{~mm}$ ), 26 July 1971 , more than 1000 specimens (ZMA), chlorinity $14900 \mathrm{mg} / \mathrm{l}$.

Description. -

Male: Maximum length almost $9 \mathrm{~mm}$. Cephalosome (fig. 5a) with hardly produced rostrum, slightly concave lateral lobe, and shallow sinus. Eye elongately reniform, black.

Meso- and pleosome unarmed, evenly rounded. Urosome somite 1 with rather distinct dorsal excavation, somites 2 and 3 rather swollen but not compressed (fig. 5b), all somites without dorsal armature. Only extremely small cuticular rugosities are found on the entire dorsum. Epimeral plates as illustrated (fig. 5c).

The first antenna (fig. 5d) has a hairy peduncle. The proportional length of the peduncle segments is about 5 to 4 to 3 . Peduncle segment 1 bears almost no dorsal armature; the ventral armature consists of 8 groups of setae; there are 3 to 5 setae in each group and the longest (more distal) setae are considerably longer than the diameter of the segment. Peduncle segment 2 bears $1+1$ termino-dorsal groups of setae and 7 groups of ventral setae, most of them much longer than the diameter of the segment. There are 4 ventral groups of setae on peduncle segment 3 . The flagellum is 19-segmented; each segment bears long setae and 1 aesthete. The accessory flagellum is fairly long and counts 5 segments.

The second antenna (fig. $5 \mathrm{e}$ ) is shorter than the first and has a hairy aspect. The antennal cone is normal (i.e. tapering and pointing foreward; cf. fig. 5a). Peduncle segment 4 shorter than 5 , with 7 ventral groups, 6 lateral groups and some 5 dorso-lateral groups of setae, the setae of the ventral groups being the longest (maximum length twice the diameter of the segment). Peduncle segment 5 with 6 ventral groups of setae (including the terminal group), 5 lateral groups and 5 dorsolateral groups of setae; the ventral setae are of the same length as those on segment 4. Flagellum 15 . segmented, proximal 6 segments with large calceoli; setae on the flagellum segments long, though shorter than those on the ventral margin of the peduncle.

The mandible palp (fig. 5f) has an unarmed basal segment. The second segment bears a proximal and a distal group of long setae; the third segment has 5 groups of A-setae, 3 groups of Bsetae; no C-setae; a long, regular row of D-setae (the proximal elements of this group slightly shorter than the distal ones), and 5 long E-setae.

The right and left palps of maxilla 1 are asymmetrical, although the right one (fig. $5 \mathrm{~g}$ ) is only slightly stouter than the left one (fig. 5h). Right, the distal armature consists of 6 rounded teeth, a dagger-like spine, and a subterminal seta. Left, there are 10 slender terminal spines and 4 subterminal setae.

Other mouth parts normal.

The first leg (fig. 6a) has a short, triangular carpus. The palm is almost straight, rather oblique, and armed with 2 palmar angle spines, 2 spines opposing the tip of the claw, and a truncated, flaskshaped medial palmar spine.

The second leg (fig. 6b) is hardly larger than the first. The carpus is likewise triangular. The propodus is parallel-sided; the short palm is almost straight, not very oblique, and armed with 3 palmar angle spines, 2 spines opposing the claw, whereas the function of the medial palmar spine is taken over by a slightly thickened seta.

The third leg (fig. 6c) is longer than the fourth, about as long as the seventh. The coxal plate is devoid of longer setae. The merus is slightly widened, armed at its posterior margin with 4 groups (including the terminal one) of setae. The 

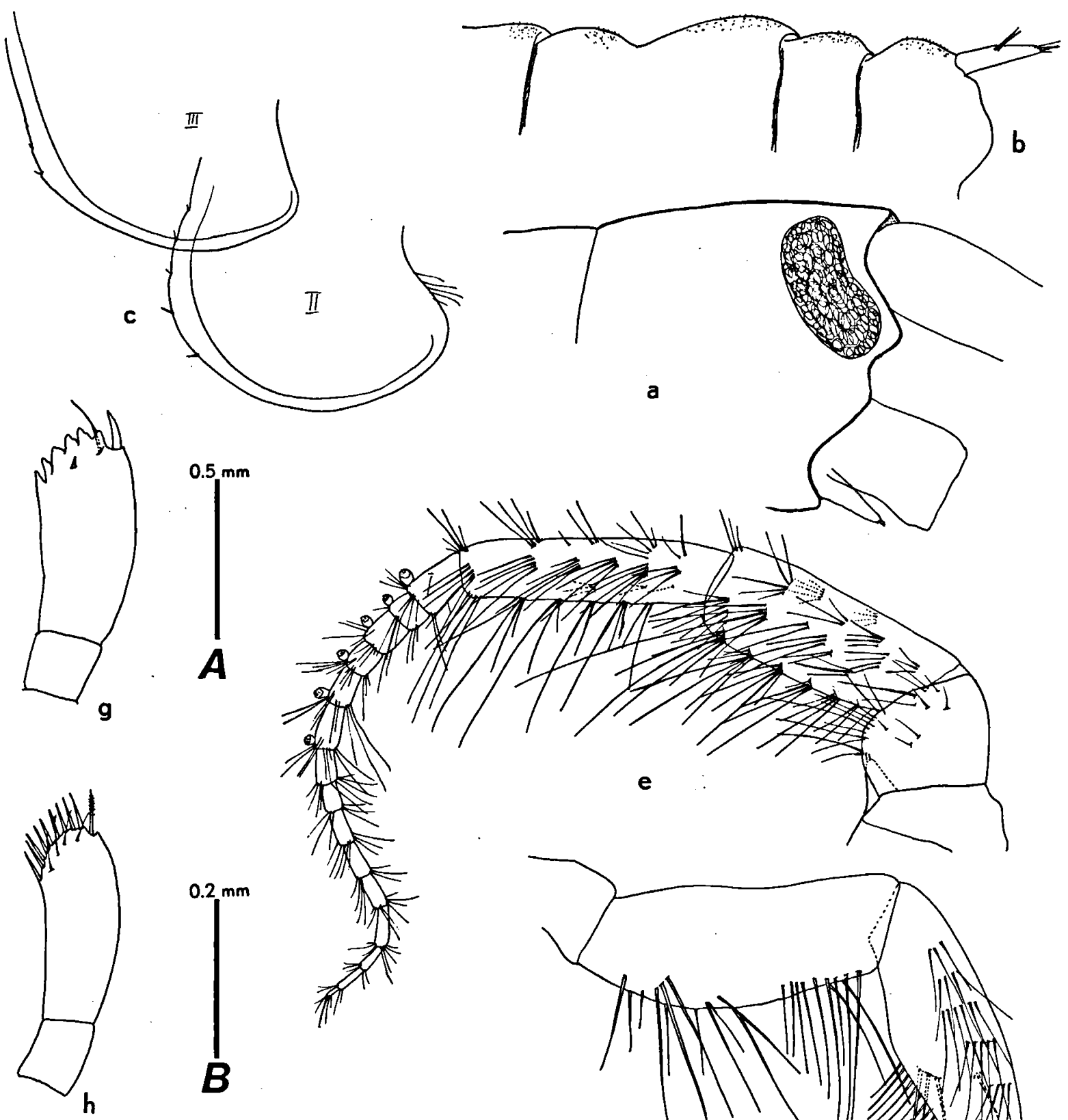

II
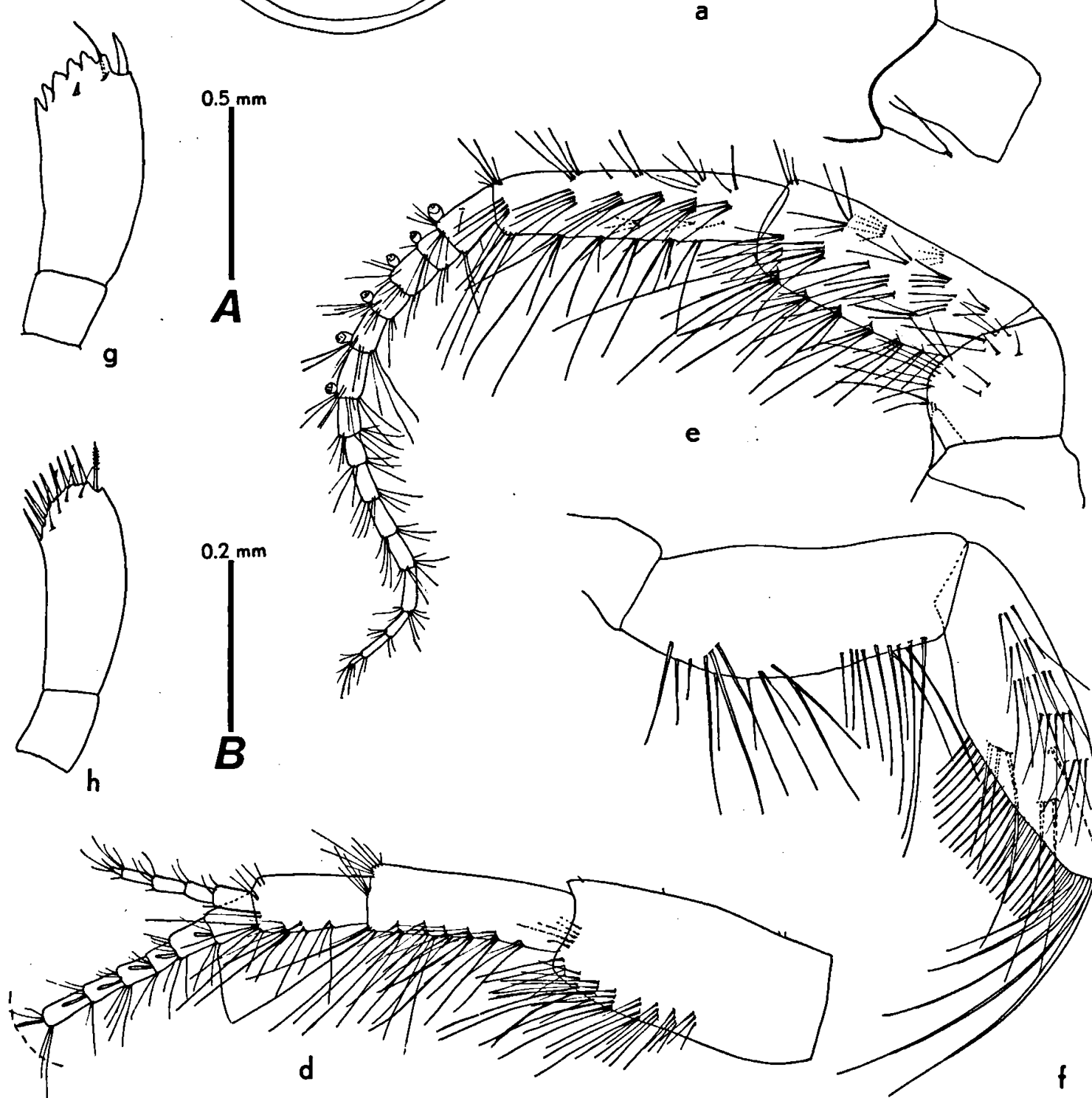

flagellum omitted (A); e, second antenna (A); f, mandible palp, fine ornamentation of the elements omitted (B); $\mathrm{g}$, palp of right first maxilla (B); h, palp of left first maxilla (B).
Fig. 5. Neogammarus nudus n. sp., $\hat{o}$, paratype, coll. ZMA a, head from the right (scale $A$ ); $b$, dorsal side of urosome from the left (A); c, epimeral plates II and III (A); d, first antenna, distal segments of 19-segmented 


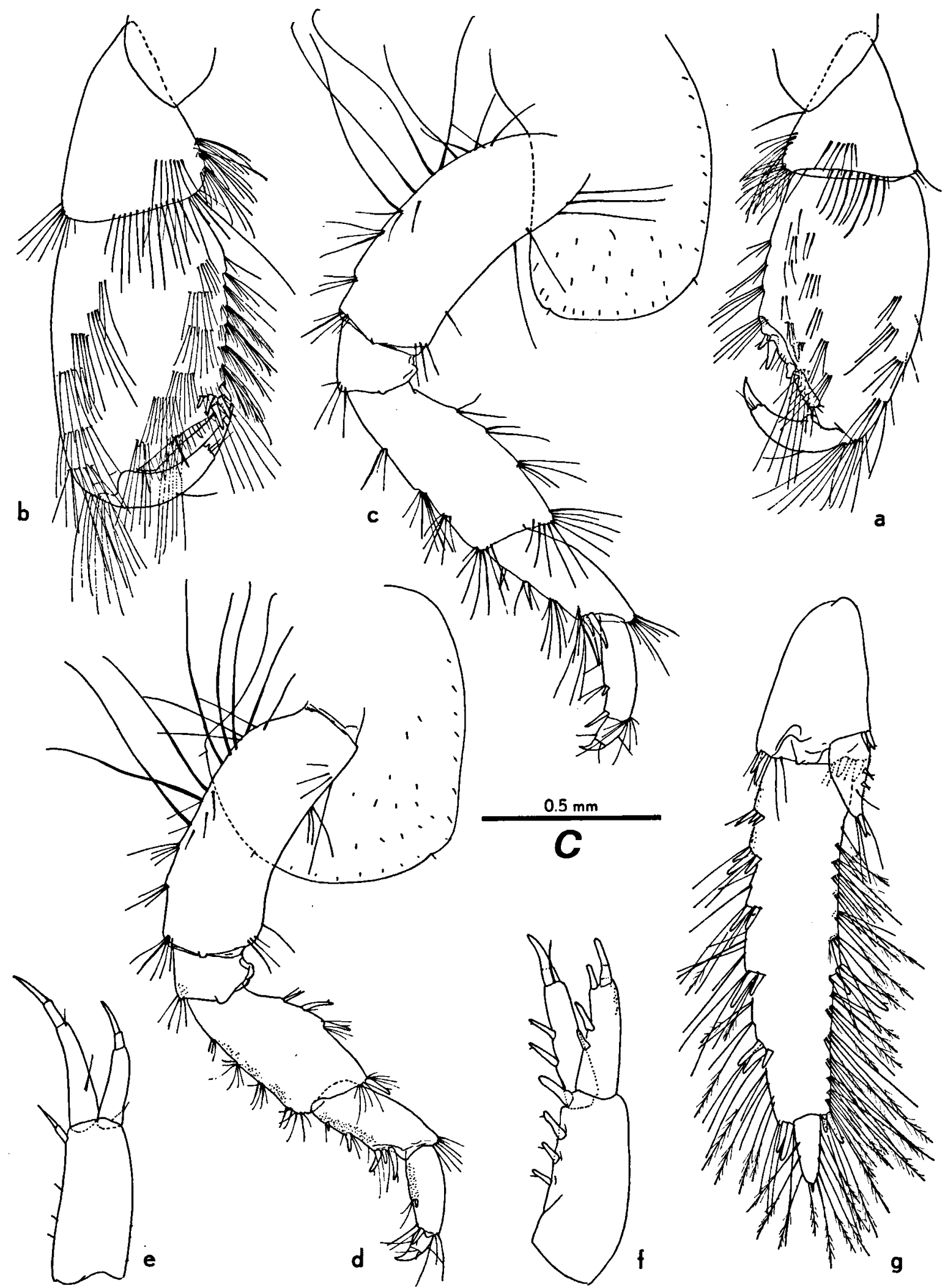

Fig. 6. Neogammarus nudus n. sp., $\hat{o}$, paratype, coll. ZMA. a, distal segments of first leg (scale C); b, distal segments of second leg (C); c, third leg (A); d, fourth

leg (A); e, first uropod (A); f, second uropod (A); g, third uropod (C). Fine ornamentation of the elements omitted in $a$ and $b$. 


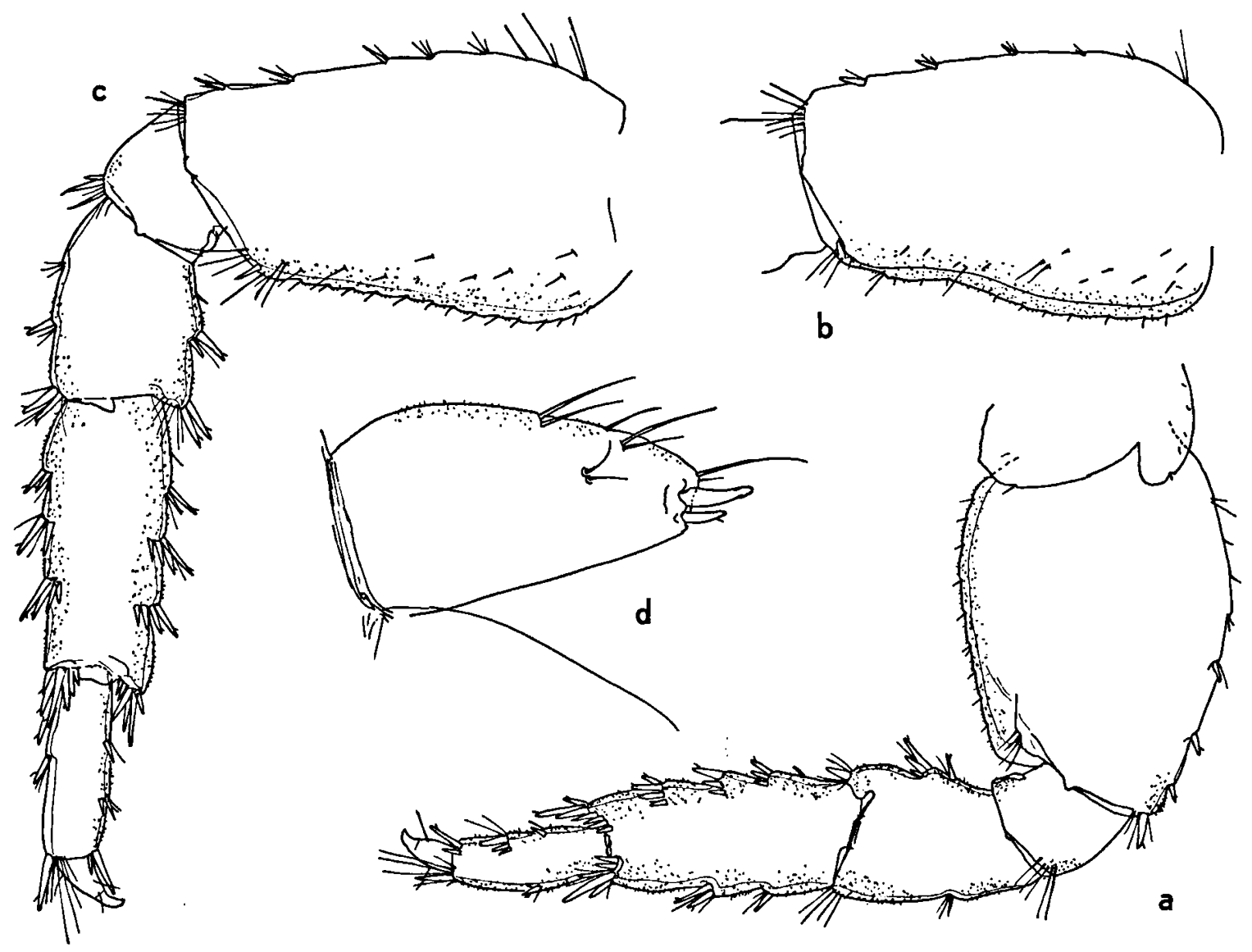

Fig. 7. Neogammarus nudus n. sp., ô, paratype, coll. ZMA. a, fifth leg (scale A); b, basis of sixth leg (A); seventh leg (A); d, telson (B).

carpus is slightly widened, and bears $1+1+3$ spines and 3 groups of setae on its posterior margin.

The fourth leg (fig. 6d) has short and wide carpal and meral segments; the setae on the posterior margin of these segments are short.

The fifth leg (fig. 7a) has a wide basal segment, the posterior and anterior margins of which are evenly curved; the posterior margin bears little numerous, short setules; the posterio-distal angle is produced into a lobe; at some distance from the lobe, a group of 3 or 4 angle setae is found. Like in legs 6 and 7, the segments of leg 5 are covered by minute cuticular rugosities. The merus is exceedingly shortened; merus and carpus are moreover widened; the propodus is shortened and widened to a lesser degree.

Similar shortening and widening of the distal segments, in particular of the merus, is found in legs
6 and 7 (figs. 7b, c). The basis of these legs has a straight or very faintly concave posterior margin, armed with regularly set, very short setules. The posterio-distal angle of the basis is not very clearly produced, armed in P6 with a few setules, in P7 with a spine and a couple of setules. The long segments of P5 to P7 are armed with groups of strong spines, each group usually provided with a setule that has a length equal to that of the spines.

The first uropod (fig. 6e) is reduced; its tip does not reach the end of the 2 nd uropod. The rami are devoid of spines, except for an articulated distal element. The inner ramus is about $1 / 3$ longer than the outer ramus.

The second uropod (fig. 6f) is short and robust, but both peduncle and rami are normally armed with strong spines.

The third uropod (fig. $6 \mathrm{~g}$ ) has a 2-segmented 
exopod, armed laterally and medially with groups of spines accompanied by long, partly plumose, setae. The endopod is tapering, about $1 / 4$ to $1 / 5$ of the length of the first exopod segment, armed with some medial setules and spinules, and some longer distal elements.

The telson lobe (fig. 7d) is not very wide; the armature consists of 1 lateral group of setae, 1 subterminal group of setae, and a terminal group of a few spines and a few setae, some of the latter slightly longer than the spines. Two "perception setules" occur on the dorsal surface of each telson lobe.

Female: Maximum length $51 / 2 \mathrm{~mm}$. No calceoli. Setation of antennae, and shape of legs 3 to 7 and uropods resembling those of the male. Propodus of legs 1 and 2 much smaller.

\section{Colour. - Whitish, opaque; eye black.}

Remarks. - The new species resembles $N$. festae in a number of striking details, above all the reduction of the first uropod, the lack of dorsal armature of the urosome, the presence of calceoli in male and of a large, black eye. The type localities are not far apart, and both species come from the same sort of habitat (surf zone of stony or shingly beaches). For these reasons, I first considered the present material identical to $N$. festae, but a more close inspection of the description of that species by Ruffo and of the new material at hand, revealed so many fundamental differences, that I feel justified to attribute the present material to a new species.

The more striking differences are: (1) left palp of maxilla 1 with 10 terminal elements in nudus, with 5 to 7 in festae; (2) palm of the 1st, but especially of the 2nd, legs straight in nudus, concave in festae; (3) one mid palmar spine on the propodus of leg 2 in festae, none in nudus; (4) propodus of $\mathrm{P} 3$ and $\mathrm{P} 4$ with spines in nudus, with setae only in festae; (5) posterior margin of basis of P5 to P7 convex to straight in nudus, concave to. very concave (P7 9 !) in festae; (6) postero-distal corner of basis of P5 strongly projecting in nudus, hardly indicated in festae; (7) exopod of first uropod $2 / 3$ as long as the endopod in nudus, half as long in festae.

The proposed specific name, nudus, refers to the unarmed dorsal side of the urosome, a feature that is shared by the present species and $N$. festae only within the gammarid-complex.

\section{Sarathrogammarus Martynov, 1935}

Sarathrogammarus Martynov, 1935: 484, 506; G. Karaman, ?1969b: 33.

Gammarus (Sarathrogammarus). - Schellenberg, 1937: 273; Dahl, 1958: 15; Ruffo, 1958: 399.

Diagnosis. - Gammaridae of the Sarathrogammarus-group. Eyes pigmented (rounded and small in the seven species known). Dorsal surface of urosome provided with spines. A2 of without calceoli. Carpus P2 $\sigma^{\pi}$ modified. P3 $\sigma^{\pi}$ modified; P3 o usually not (exceptions: $S$. guernei, $S$. multipennatus). P3 $\sigma^{x}$ much longer than P4 $\sigma^{x}$, the latter unmodified. Uropod $1\left(\sigma^{\circ} q\right)$ unmodified. Uropod $3\left(\sigma^{\prime} q\right)$ with reduced endopod and reduced terminal exopod segment. Type species (by monotypy): S. asiaticus Martynov, 1935.

\section{KEY TO THE SPECIES}

1 a) Setae on lower margin of 2 nd peduncle segment of A1 $\hat{o}$ much shorter than the diameter of the segment . . . . . . . . . . . . . . . 2

b) These setae are as long as, or longer than, the diameter of the segment . . . . . . . . . 5

2 a) Accessory flagellum 3- to 4-segmented . . . . 3

b) Accessory flagellum 2-segmented . . . . . 4

3 a) P3 $q$ modified (with numerous rows of setae on merus and carpus).

S. multipennatus G. Karaman, 1969: $204-207$, figs. 28-39 (as subspecies of $S$. lindbergi). See also G. Karaman, ?1969b: 40.

Origin: Afghanistan.

b) P3 9 unmodified (without numerous rows of setae). S. lindbergi G. Karaman, 1969: 195204, figs. 1-27. See also G. Karaman, ?1969b: 40. Origin: Afghanistan.

4 a) Palm P2 $\delta$ very oblique. Flagellum A1 $\delta$ with numerous setae.

S. afghanus (Ruffo, 1958: 396-399, fig. IV). See also: G. Karaman, ?1969b: 37-39, figs. $10-14$.

Origin: Afghanistan.

b) Palm P2 $\hat{o}$ not oblique. Flagellum A1 $\hat{o}$ with few setules only.

S. asiaticus Martynov, 1935: 485491, 507, figs. 55-61. See also G. Karaman, 21969b: 39.

Origin: Turkestan.

5 a) Palm P2 $\delta$ straight, with mid-palmar spine. Distal end of telson with spines and long setae.

S. trichiatus n. sp. Vide infra. Origin: Afghanistan.

b) Palm P2 $\hat{o}$ concave, without mid-palmar spine. Distal end of telson with spines only . . . . 6

6 a) P3 9 modified (with numerous rows of long setae on merus and carpus). Ventral side of peduncle A1 s with 2 to 4,4 to 5 , and 3 bunches of setae. 


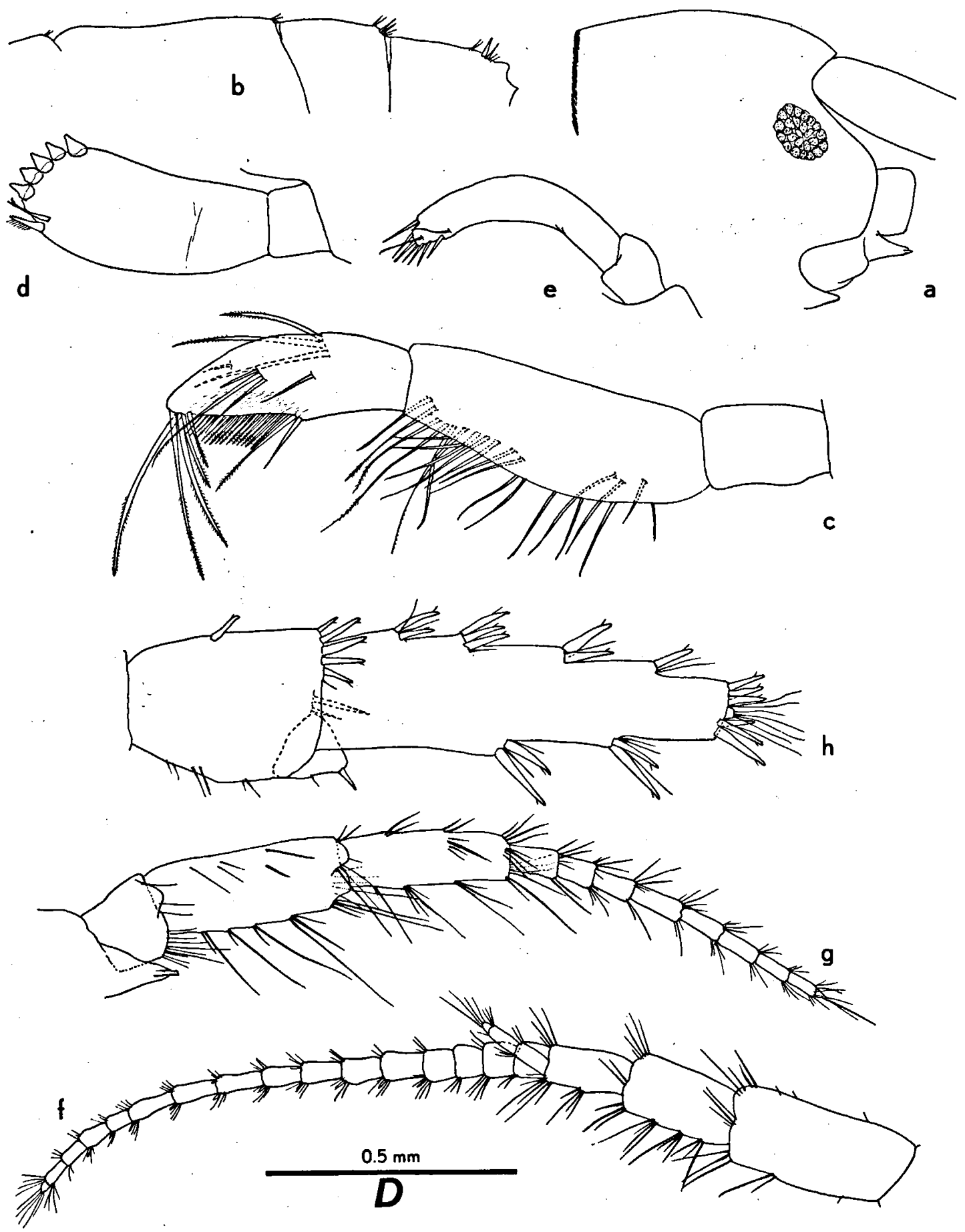

Fig. 8. Sarathrogammarus trichiatus n.sp., paratypes, coll. ZMA. a, head from the right, $A$ (scale A); $b$, urosome from the left, $\hat{o}$ (A); c, mandible palp, of (B); d, palp of right first maxilla, $\hat{o}$ (B); e, palp of left first maxilla, $\delta(B)$; $f$, first antenna, $\delta(A) ; g$, second antenna, $\delta$ (A); h, third uropod, $\&$ (D). 
S. guernei (Chevreux, 1889). Vide infra.

Origin: Azores.

b) P3 \& unmodified (without numerous rows of long setae). Ventral side of peduncle A1 8 with 4 to 5 , 8 , and 5 bunches of setae.

S. madeirensis (Dahl, 1958). Vide infra.

Origin: Madeira.

Sarathrogammarus trichiatus n. sp. Figs. 8-10.

Material examined. - 31 \& (including 1 \& holotype), 29 \%. Central Afghanistan, province Bamiyan, Band-eAmir, altitude $3000 \mathrm{~m}, 14$ Oct. 1967. The holotype and 30 paratypes are in the Zoölogisch Museum, Amsterdam (ZMA Amph. 102.913), 29 paratypes are in the Zoological-Parasitological Institute, University of Kabul, Afghanistan.

Description. - Male: Length of adult (from frontal margin of head to end of telson) about $9 \mathrm{~mm}$. The eyes (fig. 8a) are almost circular, small, but well-pigmented. The lateral lobes of the head are rounded (fig. 8a).

The dorsal side of the metasome is devoid of ornamentation, except for the few usual small cilia at the posterior margin of the somites. The dorsal contour of the urosome is flat (fig. 8b); the armature consists of a few medial cilia on the first urosome somite; urosome somites 2 and 3 each bear 2 medial cilia and 1 to 2 lateral spines accompanied by 2 cilia.

The first antenna (fig. 8f) has rather short and robust peduncle segments, ventrally armed with groups of setae; the longest setae of these groups are about as long as the diameter of the segments, or - on segment 3 - even longer; segment 1 carries 2, segment 2 carries 4, segment 3 carries 2 such groups.

The accessory flagellum is 3-segmented, the main flagellum has 15 to 21 segments. Each flagellum segment bears a tuft of well-developed setules.

The second antenna (fig. 8g) is slightly shorter than the first. The excretory cone is regularly tapering. Peduncle segments 4 and 5 bear 5 and 4 ventral tufts each of a few setae, respectively; these setae are much longer than the diameter of the segments. The dorsal armature of these peduncle segments consists of a few groups of short, little numerous setae. The flagellum bears rather long, but not very dense, setation; calceoli are absent, the flagellum consists of 8 to 9 segments.

The mouth parts are normal, i.e. they do resemble closely the typical gammarid structure, as illustrated by Sexton \& Spooner, 1940, for Chaetogammarus pirloti. The mandible palp (fig. 8c) has an unarmed first segment; the third segment has 2 groups of A-setae, 2 groups of B-setae, 2 Csetae, a row of D-setae that regularly decreases in length in distal direction, and 5 E-setae (nomenclature of the groups of elements after G. Karaman, 1970).

The first maxilla has an asymmetrical palp, of the usual type (figs. 8d, e).

The coxal plates of legs 1 to 4 lack long cilia at their ventral margin. The propodus of leg 1 (figs. 9a, b) is pear-shaped, the palm is very oblique, nearly straight or very slightly concave, and merges gradually into the posterior margin. The palmar angle is marked by a group of 4 gradated spines; the posterior margin of the propodus bears 2 extra groups of strong spines, viz. a basal group of 2, and a distal group of 3 gradated spines. The two usual short spines oppose the tip of the dactylus. The mid-palmar spine is implanted at an unusual place: it is no longer found at the palmar margin but it is displaced in proximal direction. The propodus bears remarkably few setae.

Leg 2 (fig. 9c) is practically of the same size as leg 1 . The propodus (fig. 9d) is slightly more ovate in shape. The palm is straight. The palmar angle is very clearly marked by a swelling and a large spine, the latter being one of a group of 5 . The two usually short spines oppose the tip of the dactylus. The mid-palmar spine is short, obtusely tapering, and implanted at a short distance from the distal end of the palm.

Leg 3 shows the generic diagnostic features (fig. 10a): widened meral and carpal segments, armed, like the propodus, with numerous rows of long, feathered, rumpled setae (more than 30 rows on the merus, about 24 on the carpus, and about 19 on the propodus).

Leg 4 (fig. 10c) is armed with spines and very short setae only.

Leg 5 (fig. 10d) has a rectangular, rather wide, basal segment, the posterior margin of which bears about a dozen of short setules; the longer segments are armed with rather short spines, intermixed with a few setae that are subequal to the spines.

The basis of leg 6 (fig. 10e) has a concave posterior margin.

Leg 7 (fig. 10f) has a slightly tapering basis, the posterior margin of which is nearly straight to slightly convex, and is armed with some 9 to 10 short setules. The ventroposterior corner of the 
basis bears a short spine and a setule; it is not expanded or projecting. The armature of the distal segments is as in leg 5.

Epimeres 2 and 3 (fig. $10 \mathrm{~g}$ ) have rounded to rectangular ventroposterior corners; their posterior margin is armed with several short setules, their ventral margin with a spinule.

Uropods 1 and 2 (figs. 10h, i) are well-developed, the first reaches to the end of the second. Uropod 3 (fig. 6j) has a 2-segmented exopod; the first exopod segment bears 3 to 4 groups of short lateral spines, and 2 groups of medial spines. The second exopod segment is rudimentary. The endopod is reduced, scale-like or rounded triangular, about as long as wide, and armed with a single distal spine only.

The telson (fig. 10k) consists of two ovate lobes, without lateral subbasal armature, but with 3 distal spines, and several distal setae that overreach the spines.

Female: Slightly smaller than the male. Broodplates linear. Secondary sexual differences chiefly in the propodus of legs 1 and 2 , in the armature of leg 3 , and in uropod 3 .

The propodus of leg 1 (fig. 9e) is trapezoidal, smaller than in male, without medial palmar spine. The palm is convex. The posterior margin bears, in addition to the angle group of 3 spines, only one more group of 2 spines.

The propodus of leg 2 (fig. $9 \mathrm{f}$ ) is rectangular to ovate, likewise smaller than in male. The palm is convex, and lacks a medial palmar spine. The angle group consists of 3 spines only.

Leg 3 (fig.10b) has a widened merus, but this segment bears 8 normal groups of stiff, not excessively elongated, setae. The carpus bears 2 groups of spines, intermixed with short setae, and the propodus is almost devoid of setae.

The 3rd uropod (fig. $8 \mathrm{~h}$ ) is less slender than in male. The distal exopod segment is still more rudimentary, and the spines on the first exopod segment are slightly longer than in the other sex.

Remarks. - The new species belongs to the genus Sarathrogammarus s. str., as defined above. It differs from lindbergi G. Karaman, 1969, multipennatus G. Karaman, 1969, asiaticus Martynov, 1935. and afghanus Ruffo, 1958 in having tufts of long setae on the ventral margin of the peduncle segments in $A$ 1. In the presence of these long setae (to which the proposed specific name, trichiatus, from $\Theta \varrho \iota \xi=$ hair, alludes), the new species resembles madeirensis Dahl, 1958, and guernei Chevreux, 1889. From all species attributed to Sarathrogammarus, trichiatus differs in having a midpalmar spine on male gnathopods 1 and 2 and in having long distal setae on the telson.

Sarathrogammarus madeirensis (Dahl, 1958). Figs. $1 \mathrm{i}, \mathrm{j} ; 11 ; 12 ; 13$.

Gammarus (Sarathrogammarus) madeirensis Dahl, 1958: 18-20, fig. 5; Ruffo, 1958: 399 (footnote).

Sarathrogammarus madeirensis. - Straškraba, 1967: 208.

Neogammarus madeirensis. - G. Karaman, ?1969c: 50, 51, 57; G. Karaman, 1971: 206.

Gammarus (Sarathrogammarus) n. sp., Dahl, 1959: 233.

Material examined. - 1 of (holotype) and numerous paratypes. Madeira, Faial, mouth of Ribeira do Faial, 26 Apr. 1957 (ZIL).

Remarks. - This is, according to Dahl's observations, most probably a poikilohaline species. Up to now it is only known from Madeira. Some new illustrations, based on the type material, have been incorporated in this paper (figs. 11-13).

No doubt, $S$. madeirensis is closely related to $S$. guernei from the Azores. Dahl supposed that the clearest morphological difference between these two species is found in the 5th leg, which is shorter than the 6th and 7th legs in madeirensis, but subequal to these in guernei. As a matter of fact, Chevreux's figure (1900, pl. X fig. 2a) shows a long 5th leg, but the actual material does not bear out this difference very clearly.

As far as I can judge from the material at my disposal, the following differences are noticeable: (1) peduncle segments 1 to 3 of A1 $\sigma^{*}$ with about 4 to 5,8 , and 5 bunches of longer setae, respectively, in madeirensis; with about 2 to 4,4 to 5 , and 3 bunches of shorter setae in guernei; (2) distal segment of mandible palp more slender in madeirensis; (3) propodus of $\mathrm{P} 2$ i much more elongate in madeirensis; (4) palm of P2 $q$ much more oblique in guernei; (5) propodus of P3 $0^{*}$ with $1+2$ spines in madeirensis, $1+1+1+2$ in guernei; (6) merus and carpus of P3 $q$ with short setae in madeirensis, with very long setae in guernei; (7) merus and carpus of P4 $\sigma^{7}$ slightly more slender in madeirensis; (8) basis of P7 $\sigma^{7}$ very slender, nearly parallel-sided, in madeirensis, less slender and tapering in guernei; (9) posterior side of 


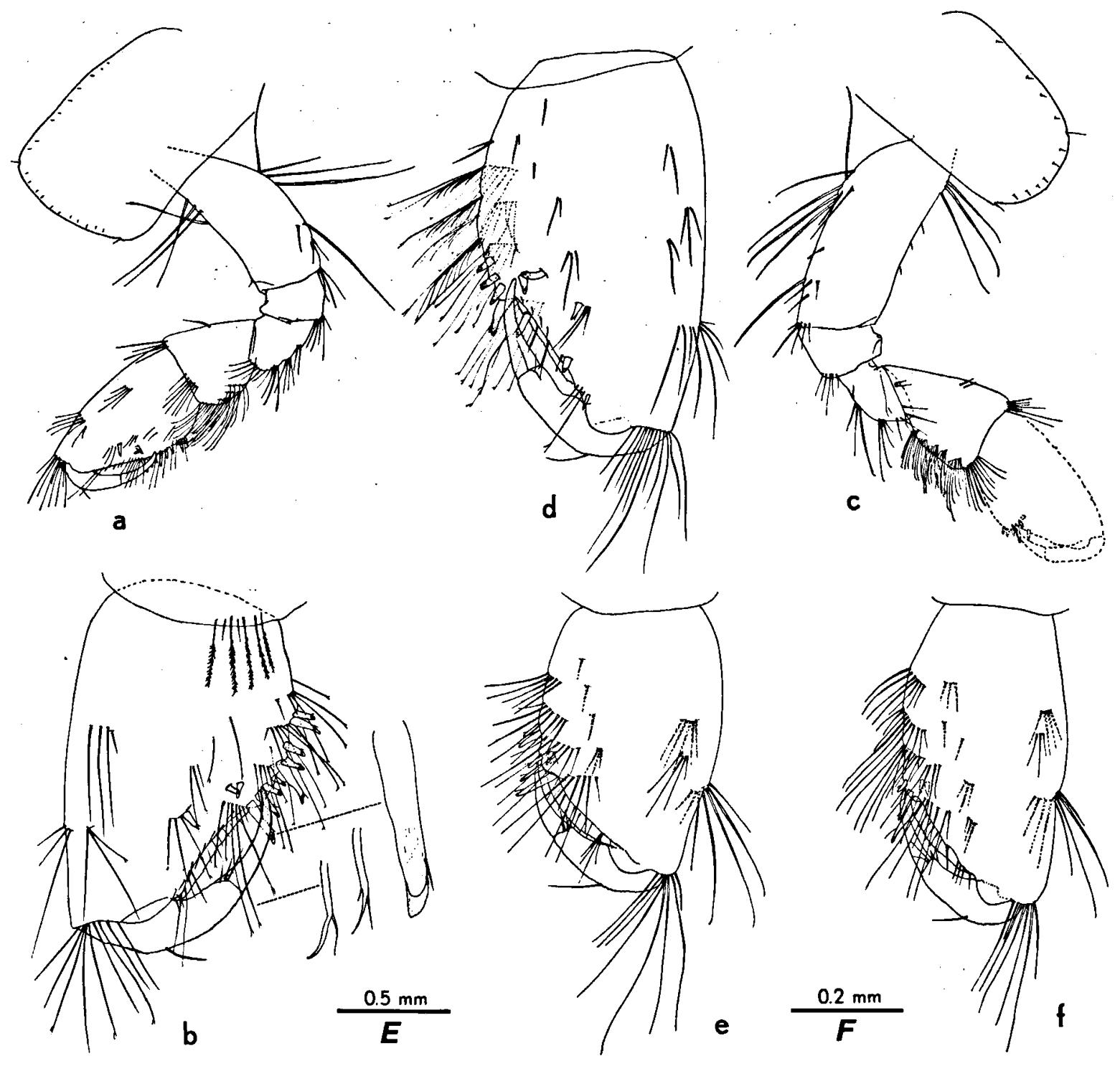

Fig. 9. Sarathrogammarus trichiatus n. sp., paratypes, coll. ZMA. a, first leg, of (scale E); b, propodus of first leg, $\hat{o}(\mathrm{~F})$; c, second leg, $\hat{\delta}(\mathrm{E})$; d, propodus of second

basis in, P7 $\sigma^{*}$ armed with 2 marginal spines in madeirensis, with 1 marginal and 1 internal spine in guernei; (10) telson lobes wider in guernei.

Variability. - The number of long terminal setae (E-setae) on the 3rd segment of the mandible palp can be 3 or 4 . In some specimens, the left and right palp even have different numbers.

Sarathrogammarus guernei (Chevreux, 1889). Figs. $1 \mathrm{~g}, \mathrm{~h} ; 14 ; 15$.

Gammarus Guernei Chevreux, 1889: 294-296, 1 fig.; Chevreux, 1900: 76-78, pl. X figs. 2a-g. leg, ô (F); e, propodus of first leg, $\$$ (F); f, propodus of second leg, $q$ (F). Fine ornamentation of the elements omitted in the figures.

Gammarus (Sarathrogammarus) guernei. - Schellenberg, 1937: 273; Ruffo, 1958: 400 (in key only); Dahl, 1959: 233.

Sarathrogammarus guernei. - Dahl, 1958: 18; Straškraba, 1967: 208.

Neogammarus guernei. - G. Karaman, 71969c: 50, 51, 57; G. Karaman, 1971: 206.

Material examined. - 2 ô, 6 \& (syntypes), labelled „Florès, Açores, Collection Ed. Chevreux", without further details ${ }^{\text {) }}$. (MNHN).

Many specimens, Flores, Azores, Ribeira d'Além da Fazenda, in a small spring, 14 Apr. 1957 (ZIL).

3) Chevreux, 1889, records the species from 4 different streams on the island of Flores. 


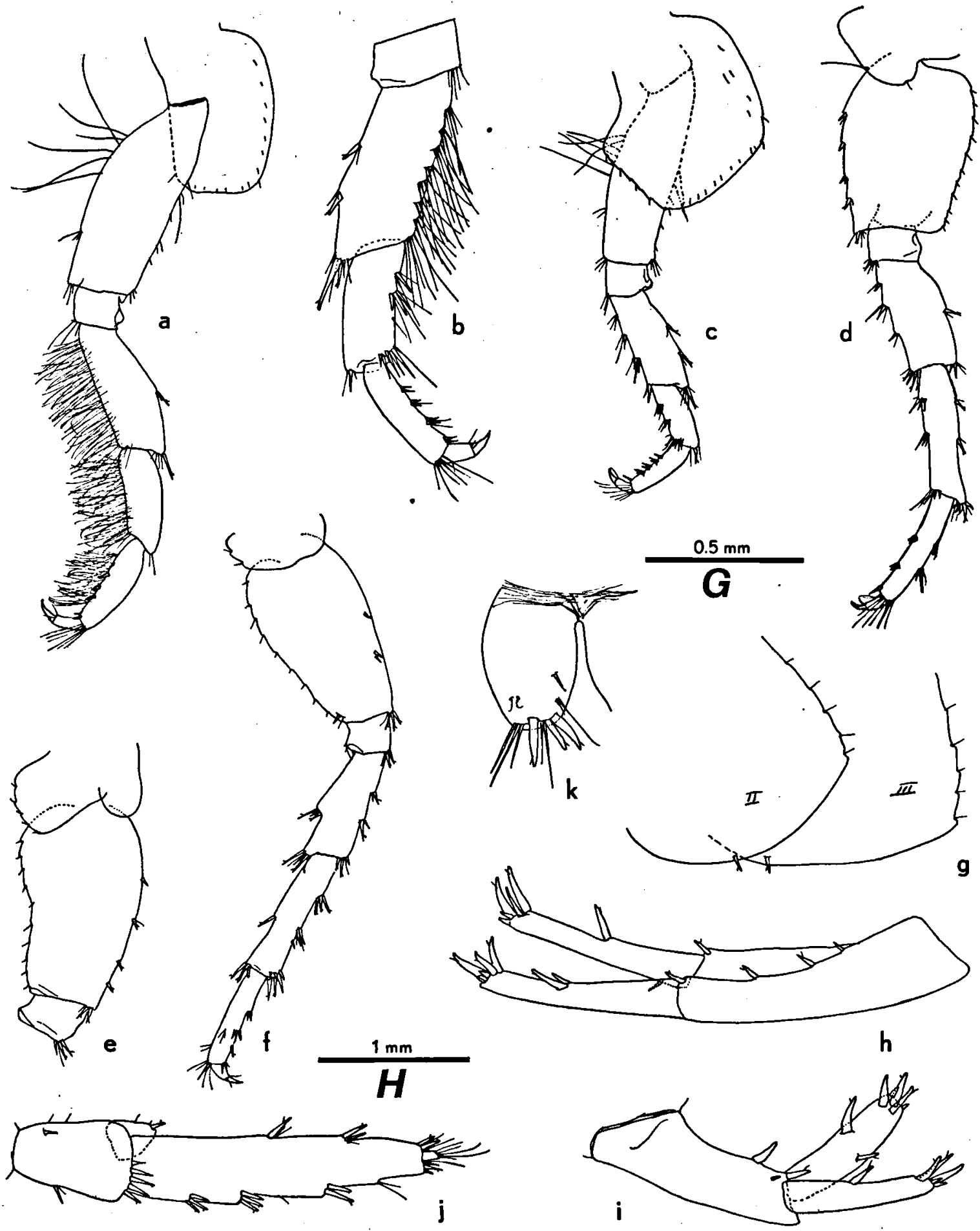

Fig. 10. Sarathrogammarus trichiatus n.sp., paratypes, coll. ZMA. a, third leg, of (scale $\mathrm{H}$ ); b, distal part of third leg, of (G); c, fourth leg, $\hat{o}(\mathrm{H})$; d, fifth leg, of $(\mathrm{H})$; e, proximal part of sixth leg, $\delta(H)$; f, seventh leg, of $(\mathrm{H}) ;$ g. epimeral plates II and III, of (A); h, first uropod, $\hat{\delta}(A) ; \mathbf{i}$, second uropod, $\hat{\delta}(A) ; j$, third uropod, ô (A); $\mathbf{k}$, telson, ô (C). 


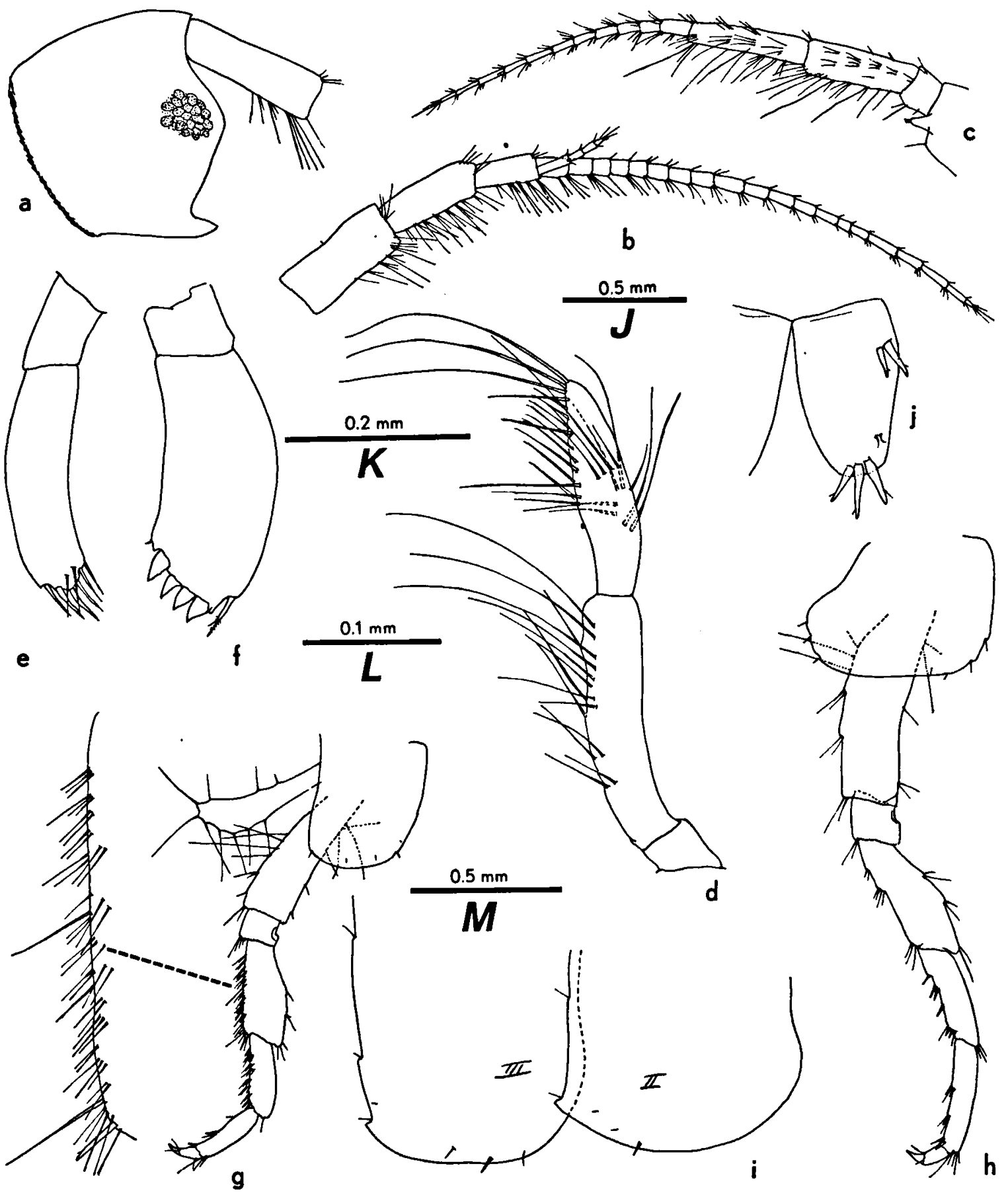

Fig. 11. Sarathrogammarus madeirensis (Dahl, 1958), paratypes, coll. ZIL. a, head from the right, of (scale A); b, first antenna, $\hat{\delta}(\mathrm{J})$; c, second antenna, $\hat{\delta}(\mathrm{J})$; d, mandible palp, $\hat{\delta}$, fine ornamentation of the elements omitted
(K); e, palp left first maxilla, ô (L); $f$, palp right first maxilla, $f(\mathrm{~L}) ; \mathrm{g}$, third leg, $\%$, with posterior margin of merus more strongly magnified (M); h, fourth leg, $\delta$ (M); i, epimeral plates II and III (A); j, telson (K). 

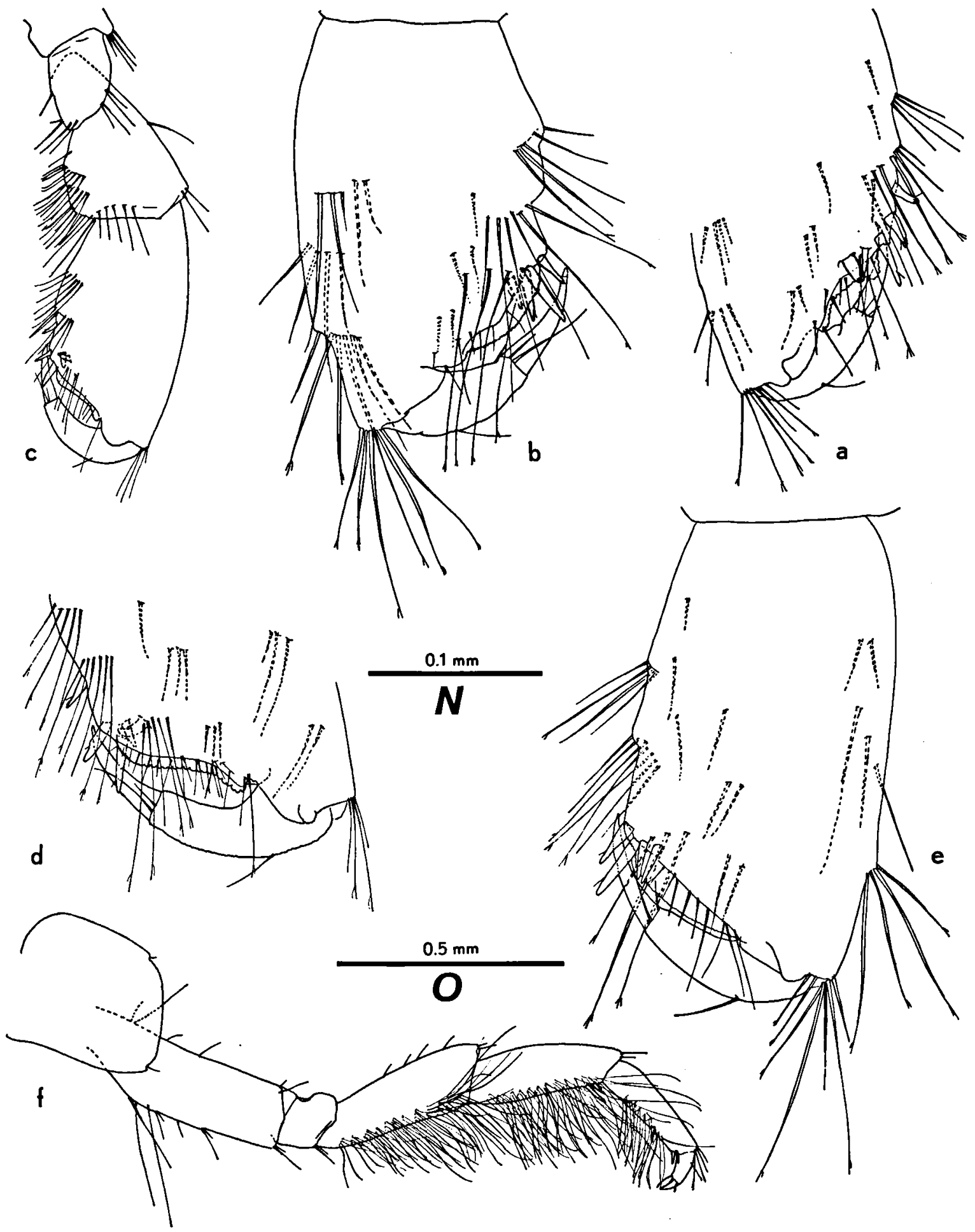

Fig. 12. Sarathrogammarus madeirensis (Dahl, 1958), paratypes, coll. ZIL. a, distal part propodus leg 1 , $\hat{\delta}$ (scale K); b, propodus leg 1 , $\%(\mathrm{~N}) ; \mathrm{c}$, distal part leg 2 ,

of (O); d, distal part of propodus of leg 2, of (K); e, propodus leg 2 , $\$(N)$; $f$, third leg, $\hat{o}(M)$. Fine ornamentation of the elements omitted in all figures. 


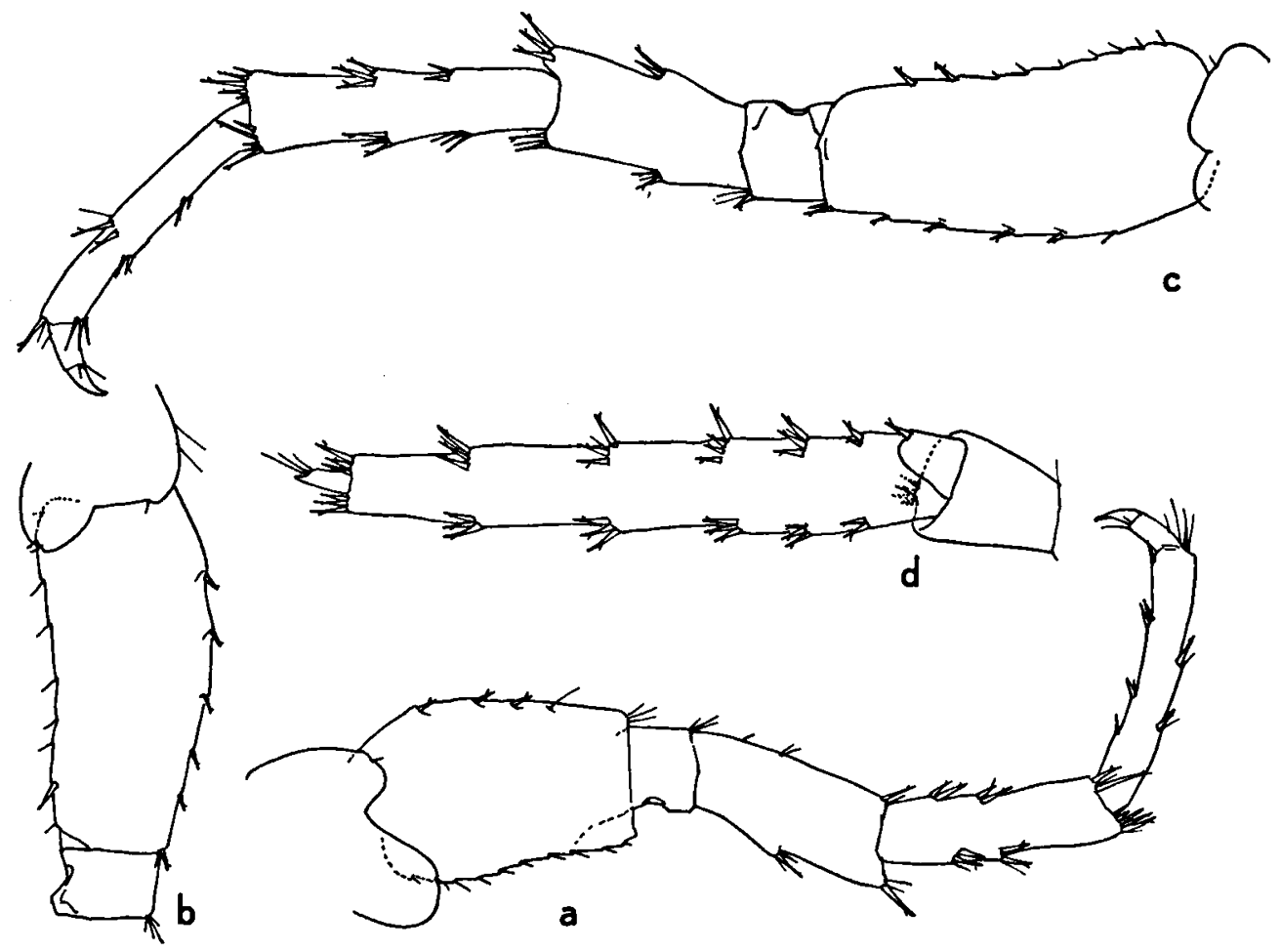

Fig. 13. Sarathrogammarus madeirensis (Dahl, 1958), $\hat{\delta}$, paratype, coll. ZIL. a, fifth leg (scale M); b, proximal

Remarks. - This species was extensively described by Chevreux, 1900. A number of new illustrations, made from the specimens recorded by Dahl, are incorporated in this paper (figs. 14-15). Up to now, $S$. guernei is exclusively known from fresh streams on the island of Flores in the Azores.

For the differences of this species with $S$. madeirensis, see remarks under the latter species.

Variability. - As far as can be judged from the two samples at hand, the variability within this species is similar to that found in other gammarids. So, the basis of $\mathbf{P 7}$ is more slender in male than in female; and it is slightly more slender in older specimens than in younger (cf. figs. $15 \mathrm{~h}$ and 15i). The 3rd uropod as well becomes slightly more elongated in very old ("senile") males (figs. 14g and 14h), as do the peduncle segments of $\mathrm{Al}$ (figs. 14a and 14b).

\section{Comatogammarus n. gen.}

Diagnosis. - Gammaridae, Sarathrogammarusgroup. Eyes pigmented (rounded in the single species known). Dorsal surface of urosome with re- part sixth leg (M); c, seventh leg (M); d, third uropod (G).

duced spiny armature. A2 $\sigma^{*}$ without calceoli. Carpus P2 trapezoidal. P3 and P4 $\sigma^{*}$ modified (with numerous rows of setae on merus and carpus), P3 and P4 $q$ unmodified. Uropod 1 unmodified. Uropod 3 with reduced endopod and vestigial apical exopod segment.

Type species. - Sarathrogammarus ferghanensis Martynov \& Behning, 1948: 171-173, figs. 1-4. (origin: Tadzhikistan, about $38^{\circ} 30^{\prime} \mathrm{N}, 70^{\circ} 46^{\prime} \mathrm{E}$ ). Remarks. - G. Karaman, ?1969b: 35-37, figs. 1-9, described material from Afghanistan that he attributes to $C$. ferghanensis. This material differs from the types in the more elongate 3rd uropods, and the absence of rows of setae on the propodus of P4 $\sigma^{*}$. Whether Karaman's material represents a different species within the genus Comatogammarus remains unsettled for the moment.

\section{Rhipidogammarus n. gen.}

Diagnosis. - Gammaridae, Sarathrogammarusgroup. Eyes pigmented (rounded in the two species known). Dorsal surface of urosome with spiny armature. A2 $\sigma^{*}$ without calceoli. Carpus P2 $\sigma^{*}$ modified. P3 ( $\left.\sigma^{*}+\right)$ modified. P3 $\sigma^{\pi}$ much longer 


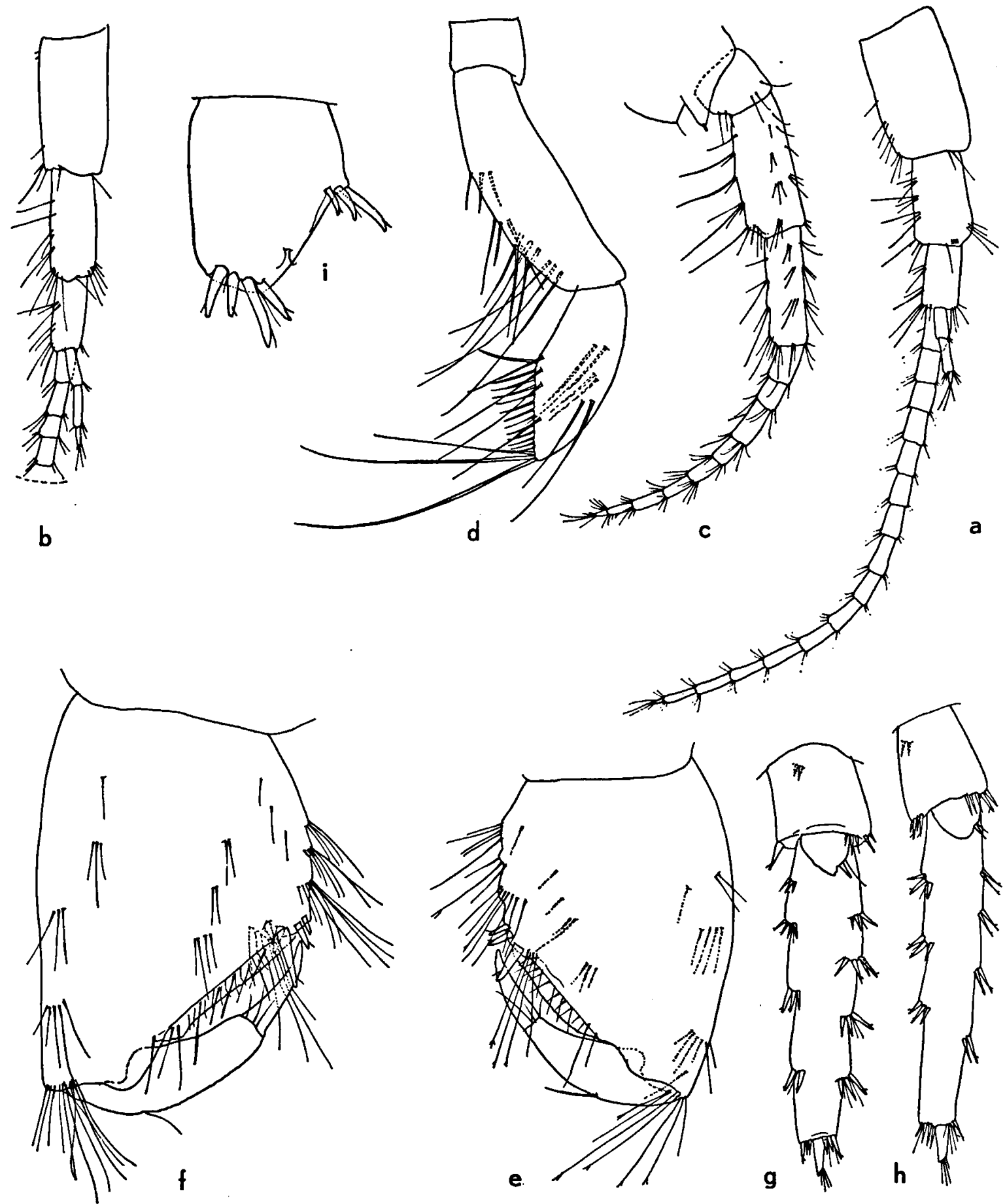

Fig. 14. Sarathrogammarus guernei (Chevreux, 1889), from Flores, Azores, coll. ZIL. a, first antenna, ô (scale $G) ; b$, proximal part of first antenna of an old male (G); c, second antenna, of (G); d, mandible palp, \& $(\mathrm{K})$; e, propodus first leg, $\%$ (K); f, propodus second leg, $q$ $(\mathrm{K}) ; \mathrm{g}, \mathrm{h}$, third uropods of two different males (G); $\mathrm{i}$, right telson lobe $(\mathrm{K})$. Fine ornamentation of the elements omitted in d, e, and $f$. 

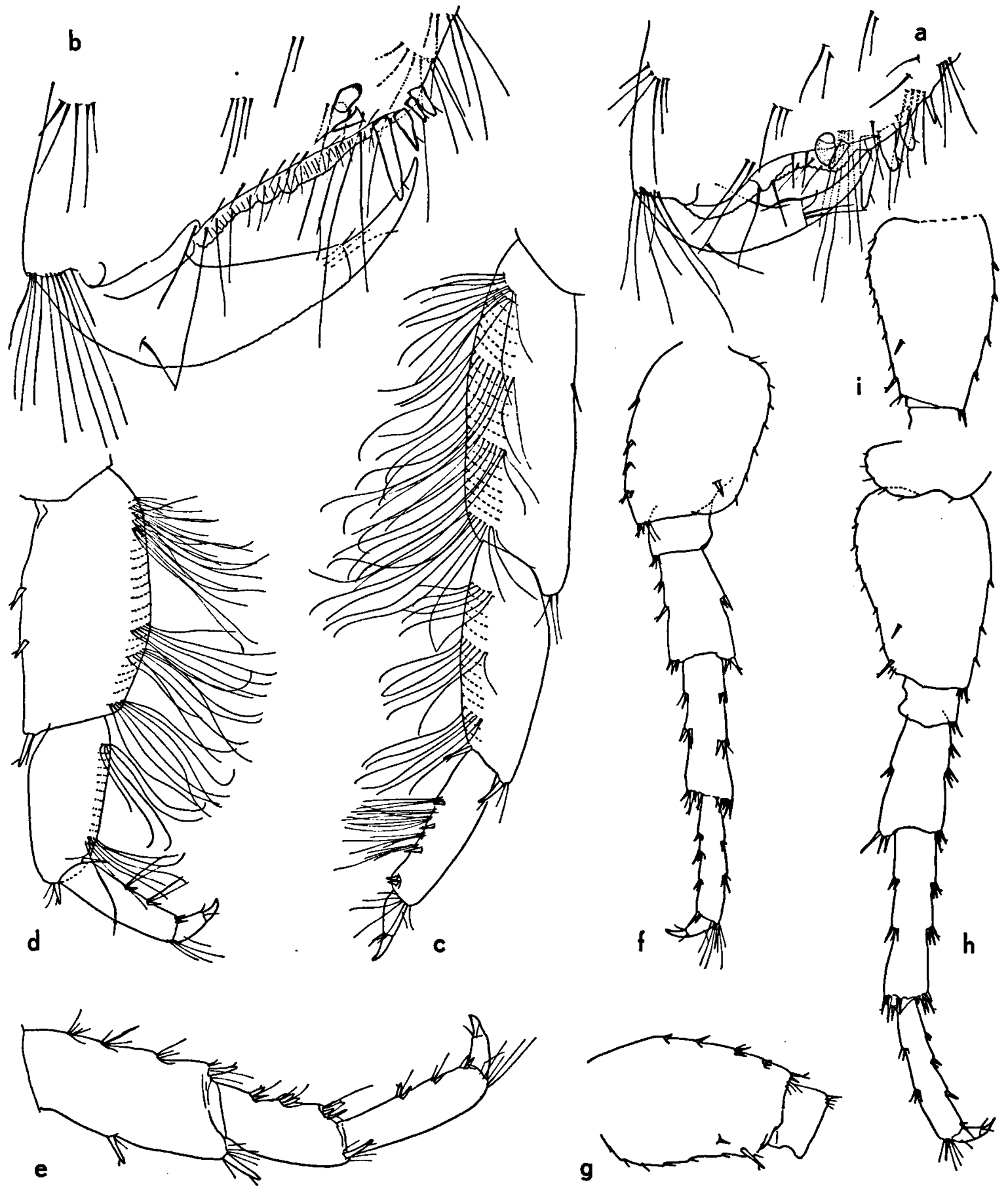

Fig. 15. Sarathrogammarus guernei (Chevreux, 1889), from Flores, Azores, coll. ZIL. a, distal part propodus leg 1, o (scale G); b, distal part propodus leg 2, $\delta$ (G); c, distal part third leg, $\delta(O)$; d, distal part third leg, $\$$
(O); e, distal part fourth leg, of (O); f, fifth leg, of (J); $\mathrm{g}$, proximal part sixth leg, of (J); h, seventh leg, of (J); $i$, basis seventh leg of old male $(J)$. Fine ornamentation of the elements omitted in a, b, c, and d. 
than P4 $\sigma^{x}$, the latter unmodified. Uropod $1\left(\sigma^{*}+\right.$ ) reduced. Uropod 3 ( $\sigma^{*}$ ) with reduced endopod and reduced terminal exopod segment.

Type species: Gammarus rhipidiophorus Catta, 1878.

\section{KEY TO THE SPECIES ( $\hat{\alpha}$ )}

1 a) Exopod of uropod 3 with numerous long, plumose setae. Setae on inferior margin of peduncle segments 4 and 5 in $A 2$ long.

Rh. rhipidiophorus (Catta, 1878)

b) Exopod of uropod 3 with very few setae, that are not overreaching the spines. Setae on inferior margin of peduncle segments 4 and 5 in A2 short.

Rh. karamani n. sp.

Variability. - The females in this genus show little secondary sexual differentiation; as a matter of fact there is hardly any or no dimorphism in the A1, A2, mouth parts, P4 to P7, and uropods. The sexual dimorphism is chiefly restricted to the shape and size of the propodus of $\mathrm{P} 1$ and $\mathrm{P} 2$, and to the setation of the propodus of P3. The latter characteristic is the most readily observed. According to Chevreux, 1901, and later authors, in male the merus, carpus, and propodus bear numerous "fans" of setae, whereas in female these "fans" are limited to merus and carpus. In the material at our disposal, this observation could be confirmed only partially: males do indeed always possess long setae on the propodus, but one can find side by side females having setae on the merus only, and females having setae on merus and carpus.

The number of setae on the legs of Gammaridae usually increases in correlation with the animal's age. In Rhipidogammarus this correlation proved to be correct for the number of setae on each segment: the largest (oldest) males have more groups of "fans", and more and longer setae in each group (cf. figs. 18a and 18c). In females the correspondence was less clear. It is true, that young females still lack the dense setation on P3 (fig. 18d), but individuals with as well as those without setation on the carpus (figs. 19d and 19e) both possessed well-developed, hairy marsupial plates, thus are sexually mature. Some ovigerous females in our collections proved to lack carpal setation. The rule that adults always are more hairy than juveniles, must be handled with care, therefore, in this group. No other morphological indication was found that females with bold and with hairy carpal segments should be reckoned to different species.

In addition to these variations in the setation of the third leg, only variability of minor importance has been observed. So, the number of palmar angle spines in P2 $\sigma^{*}$ usually is 2 , but sometimes a small third spine is found. On the posterior margin of the merus in P5 of Rh. rhipidiophorus usually only 1 group of spines occurs, but sometimes 2 groups are observed. Similarly, the normal number of groups of spines on the posterior carpal margin of P5 is 2 , but exceptionally it is 3 .

Rhipidogammarus rhipidiophorus (Catta, 1878). Figs. 16-18.

Gammarus Rhipidiophorus Catta, 1878: 256-261.

Gammarus rhipidiophorus. - Chevreux \& Guerne, 1892: 140; Chevreux, 1910: 226-227, pl. XV figs. 21-25; Chevreux \& Fage, 1925: 249-250, fig. 260; Gauthier, 1936: 136; Pacaud, 1952: 96, fig. 1; Berner, 1966: 471475.

? Gammarus rhipidiophorus. - Chevreux, 1901: 216222, figs. $1-2$.

Niphargus rhipidiophorus. - Stebbing, 1888: 475; Stebbing, 1906: 410.

? Ostiogammarus rhipidiophorus. - S. Karaman, 1931: 61.

Gammarus (Neogammarus) rhipidiophorus. - Ruffo, 1937: 440-445; Ruffo, 1939: 59, 61; Ruffo, 1951: 1-3; Ruffo, 1958: 399; Ruffo, 1960: 174-176.

Neogammarus rhipidiophorus. - S. Karaman, 1950 (pro parte, only Tunisian record): $175-186$, figs. 3, 15; Barnard, 1958: 63; G. Karaman, 21969c: 47-58 (pro parte, only the Nice record); Sket, 1969: 148; G. Karaman, 1971: 206.

Gammarus (Sarathrogammarus) rhipidiophorus. Schellenberg, 1937: 273; Dahl, 1959: 233.

Sarathrogammarus rhipidiophorus. - Straškraba, 1967: 208.

Material examined. Spain:

- Puerto de la Selva (prov. Gerona), in mouth of nearly dry river closed off by a sand dam from the sea, 3 Sep. 1961, many specimens (ZMA).

France:

- Carry-le Rouet (dép. Bouches-du Rhône), in a brackish spring near the shore, 10 Feb. 1960, 1 of (ZMA); 3 specimens with same data (MNHN). Carry-le Rouet, Calanque des Sources Salées, in brackish spring near the shore, 24 July 1971, many specimens (ZMA), chlorinity $5900 \mathrm{mg} / 1$.

- Surroundings of Marseille (dep. Bouches-du-Rhône), 1960 , without further details, 2 specimens (MNHN).

- Bouches-du-Loup (dép. Alpes-Maritımes), mouth of river Loup, in mixohaline area, cobbles and coarse sand, various dates in July 1971, many specimens (ZMA), chlorinity $32-37 \mathrm{mg} / \mathrm{l}$. 

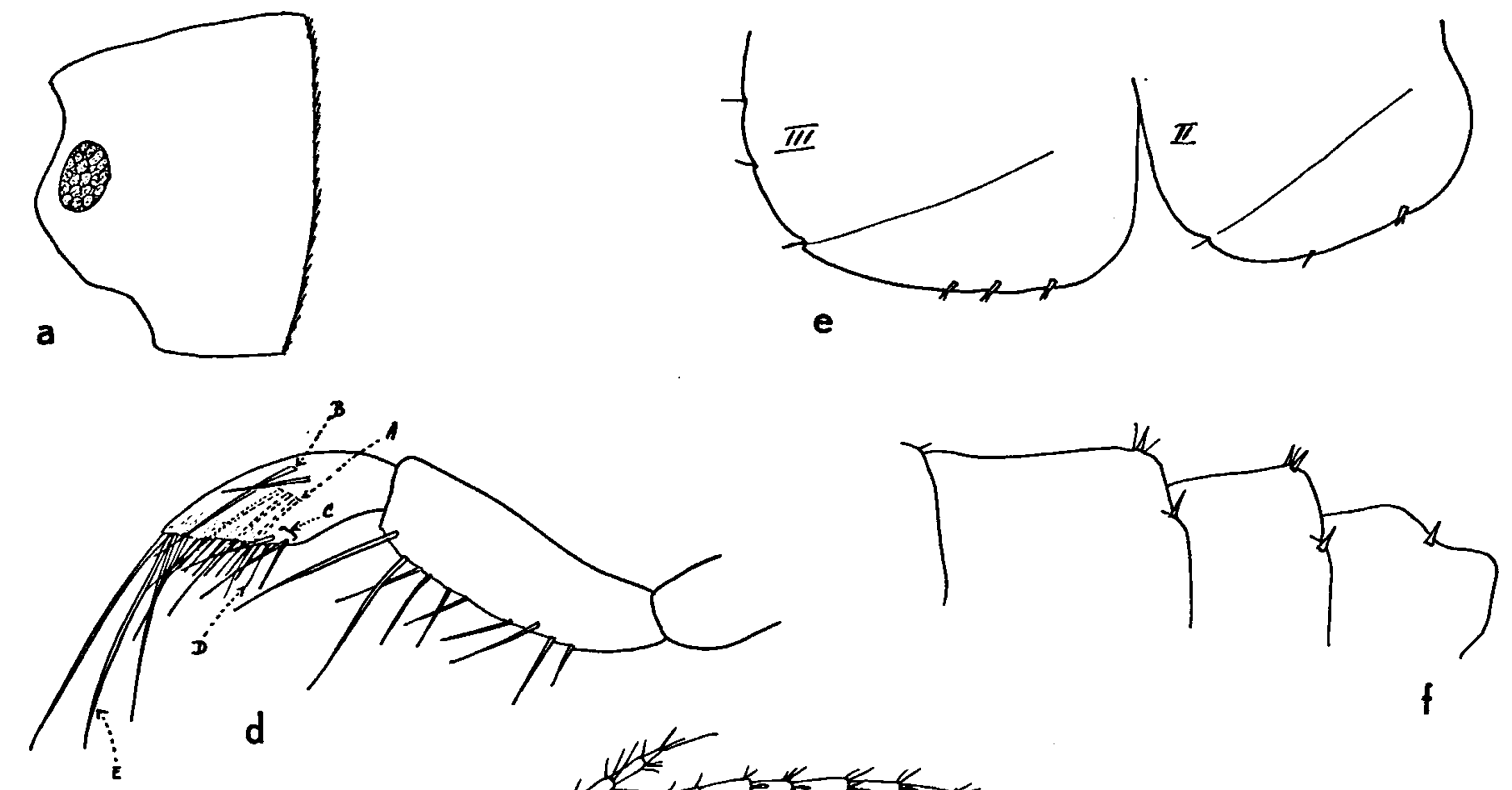

d

b
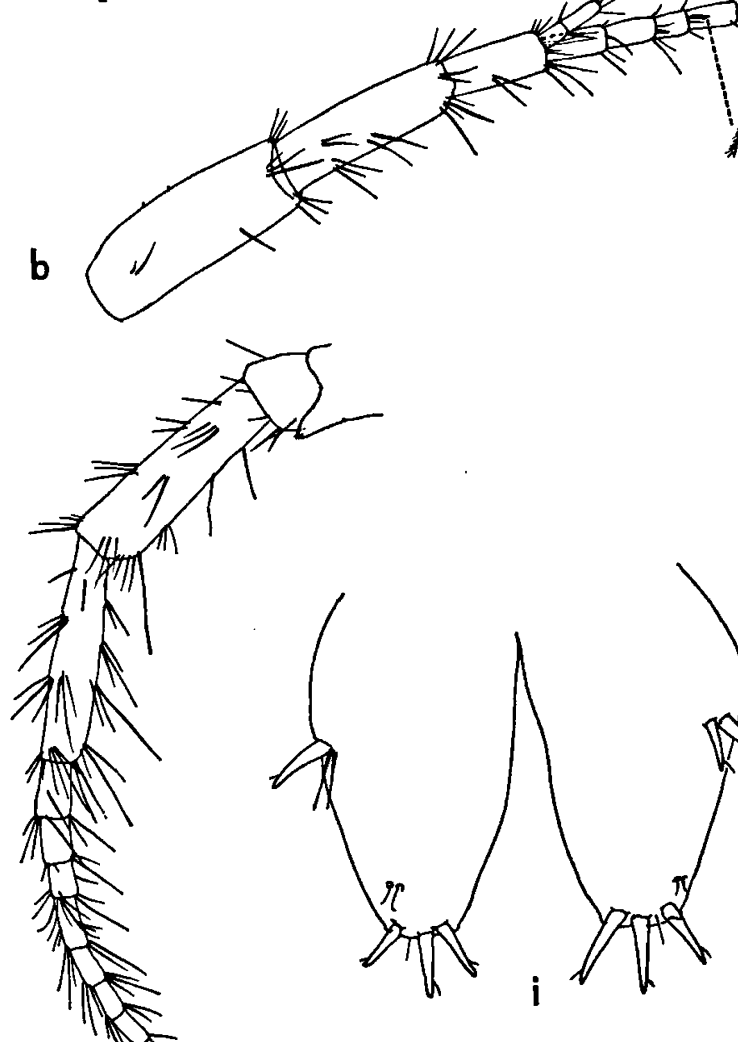

c
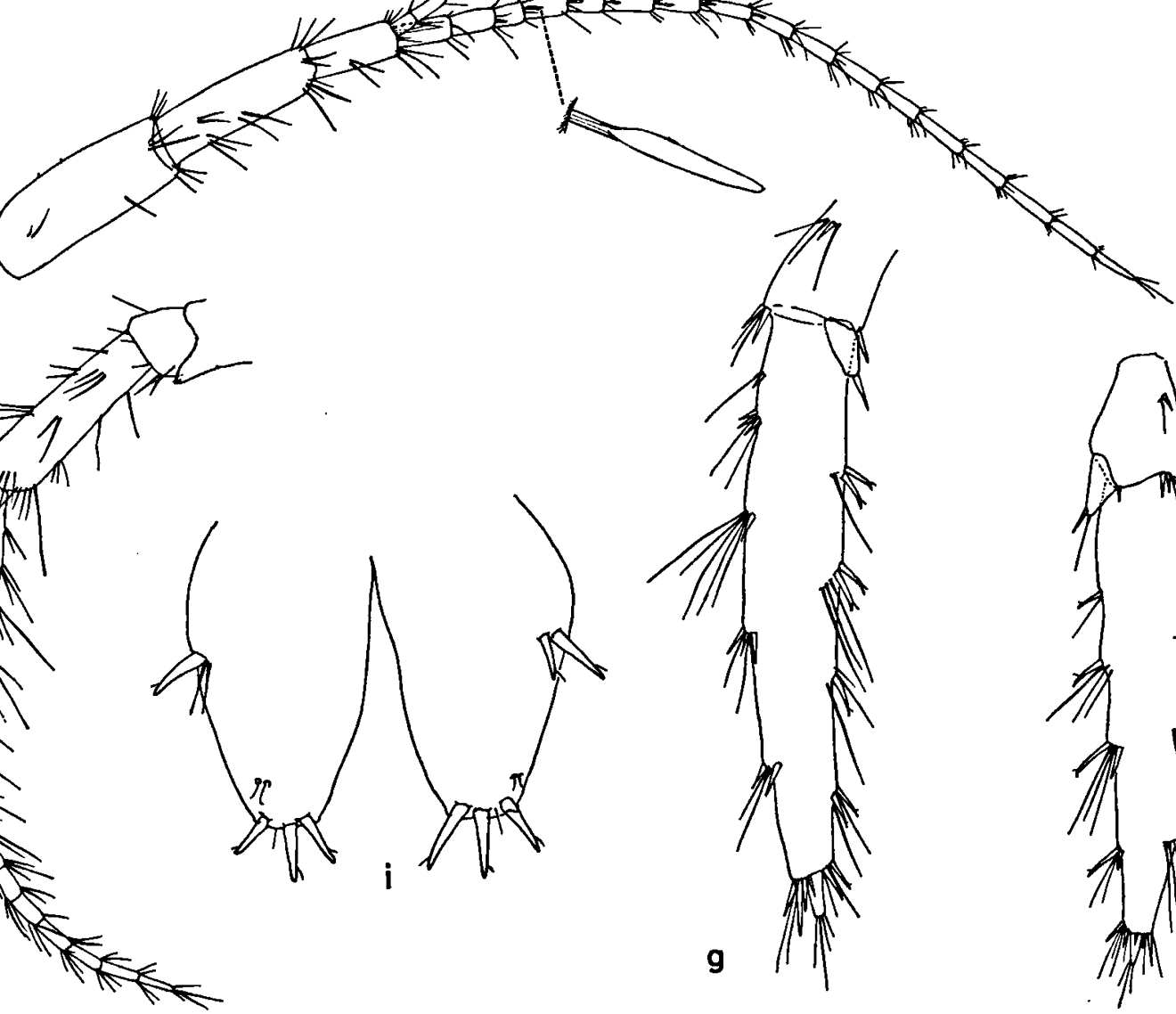

Fig. 16. Rhipidogammarus rhipidiophorus (Catta, 1878), $\hat{o}$, from Miomo, Corsica, coll. ZMA. a, head from the left (scale A); b, first antenna, with aesthete, more strongly magnified (A); c, second antenna (A); d, mandible palp (B), fine ornamentation of the elements omitted; e, epimeral plates II and III (C); $f$, dorsal contour of urosome from the left $(C) ; g, h$, third uropod of two different specimens (A); $i$, telson (B). 


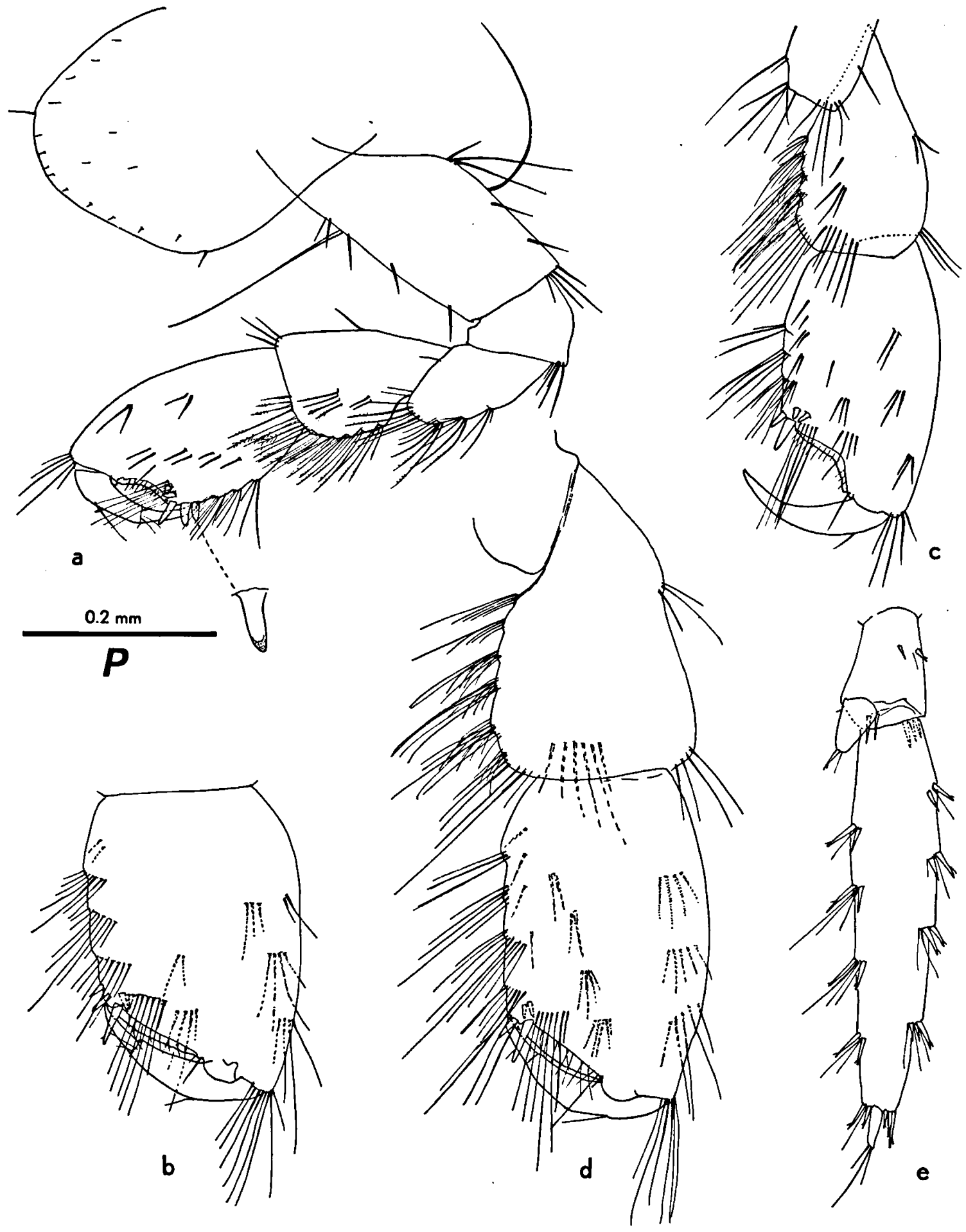

Fig. 17. Rhipidogammarus rhipidiophorus (Catta, 1878), from Miomo, Corsica, coll. ZMA. a, first leg, os (scale P); b, propodus of first leg, + (B); c, distal part of second leg, of (P); d, distal part of second leg, $\$$ (B); $e$, third uropod, $\&$ (C). Fine ornamentation of the elements omitted in $a, b, c$, and $d$. 
- Cros-de-Cagnes (dép. Alpes-Maritimes), mouth of river Cagne, mixohaline zone, in gravel, 26 July 1971, many specimens (ZMA), chlorinity $41 \mathrm{mg} / 1$.

- Miomo, Cap Corse (Corsica), in cobbles where a brook discharges on the beach, 21 Dec. 1970, chlorinity $53 \mathrm{mg} / 1,18$ specimens (ZMA).

- Lavasina, Cap Corse (Corsica), in cobbles where a brook discharges on the beach, 21 Dec. 1970, chlorinity $28 \mathrm{mg} / 1$ (but during gales no doubt much higher), 5 specimens (ZMA).

- Marine di Giottani, N. of Nonza (Corsica), cobble beach, 21 Dec. 1970, 1 \& (identification under reservation) (ZMA).

- Mouth of river Porto, near La Marine de Porto (Corsica), in gravel, 23 Dec. 1970, chlorinity 4600 mg/1, 19 specimens (ZMA).

Italy:

- Grotta Ascenso, Capo di Varigotti (Liguria), 18 Apr. 1946, many specimens (MCV).

- Grotta di Cersuta, near Maratea, 1953, 1 ㅇ (MCV).

- Cala Grande, Mte. Argentario (Toscana), in a well on $20 \mathrm{~m}$ from the sea, 12 July 1955, 9 specimens (MCV).

- Cala Gonone, Golfe di Dorgali (Sardinia), in a spring, 5 June 1955, 4 specimens (MCV). Same loc., 24 July 1955, many specimens (MCV).

\section{Algeria:}

- Oued Hadjer, N.W. of Médenine, in reservoir of a well, growth of Chara, 7 July 1970, 20 specimens (ZMA).

- Dar el Oued, 20 Sep. 1946, 20 specimens (MNHN).

Tunisia:

- Island of La Galite ( $=$ Jeziret Jālita), on the shore of a pond, in the village, altitude about $100 \mathrm{~m}, 16$ July 1901, 14 specimens (MNHN).

- Island of La Galite, Fontaine de la Plage, cobbles, altitude about $20 \mathrm{~m}, 17$ July 1901, many specimens (MNHN).

- Island of La Galite, fresh water spring, no further data, 3 specimens (MNHN).

- Ben Gardane (= about $80 \mathrm{~km}$ E. of Médenine), in a well, coll. H. Gauthier, 10 specimens (MNHN).

- Dehibat (= near Libyan border), in a well, coll. $M$. Seurat, 12 specimens (MCV).

Libya:

- Misurata (= Misratah), in well of the village, Nov. 1912,1 \% (MCV).

Remarks. - This species is amply described in various publications. A completely new set of figures is incorporated in the present paper (figs. 16-18), chiefly to show the differences between this species and the closely related $R h$. karamani n. sp.

$R h$. rhipidiophorus is recorded from a wide area and from a variety of habitats. It is known from inland waters, wells, springs, brackish sources, caves with marine influences, slightly brackish mouths of small streams, etc.:

- Fresh wells, e.g. at Dehibat, Tunisia (which is situated some $130 \mathrm{~km}$ inland, near the Libyan border) and other places in Tunisia ${ }^{4}$ ).

- Fresh springs or ponds, e.g. the records from the island of La Galite, Tunisia, from altitudes of 20 and $100 \mathrm{~m}$ above sea-level, respectively, and accompanied by the fresh water species Echinogammarus simoni, see Chevreux, 1910.

- Brackish wells or sources, e.g. Carry - le Rouet, southern France (cf. Berner, 1966), and the nearby type-locality, La Ciotat; Misurata, Libya (Ruffo, 1939); Cala Gonone, Sardinia (Ruffo, 1960).

- Caves with marine influences, e.g. Grotta di Cersuta near Maratea, Italy (Ruffo, 1951, 1960), Grotta Ascenso, Capo di Varigotti, Italy (Ruffo, 1951).

- Mouth of small streams, more in particular where water trickles over the beach, e.g. Puerto de la Selva (Spain), and various Corsican records.

The colour of life specimens is pale, intestine dark gray, eye black; pleo- and urosome tinged rosa.

Neotype selection. - Since Catta's type specimens can no longer be located (see also Chevreux \& Guerne, 1892: 140, footnote; and Pinkster, 1969: 137), it seemed justified for the stability of nomenclature to select a neotype for $R h$. rhipidiophorus (Catta, 1878), especially since a closely related species is described in the sequel. In my decision which of the two species at hand should be named rhipidiophorus, I had myself guided by two considerations: (1) The first illustrations of the species (Catta's description was not accompanied by figures) were those of Chevreux, 1901 and 1910, based on specimens from La Galite, Tunisia. These specimens have been re-examined and the present designation of a neotype is in agreement with Chevreux's notion of the species. (2) The neotype locality is choosen as close as possible to the original type locality, and the ecological conditions prevailing in both localities are more or less the same (mixohaline groundwater). Catta found his material "dans un puits situé à la Ciotat (Bouches-du-Rhône, France), à une centaine de mètres de la côte méditerranéenne". The neotype

4) Gauthier, 1936: 136, states that specimens of $R h$. rhipidiophorus are "ordinaires" in wells in the region between Gabès and Médenine. 


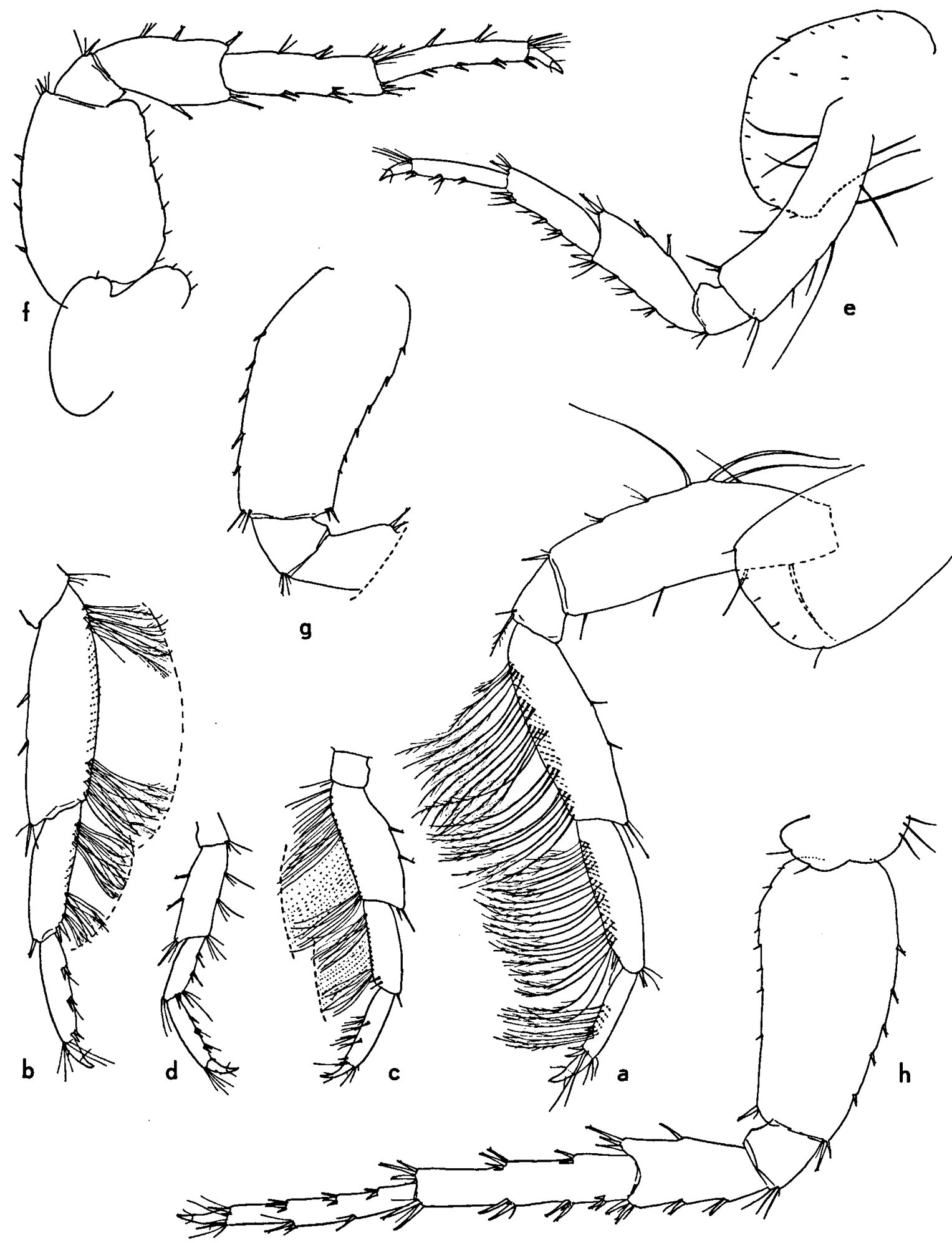

Fig. 18. Rhipidogammarus rhipidiophorus (Catta, 1878), from Miomo, Corsica, coll. ZMA. a, third leg, ô (scale A); b, distal part of third leg, $f$ (A); c, distal part of third leg, juvenile $\hat{\delta}$ (A); d, distal part of third leg, juvenile $\%$ (A); e, fourth leg, of (A); f, fifth leg, of (A); $\mathrm{g}$, basal part of sixth leg, $\hat{o}$ (A); h, seventh leg, $\hat{\delta}$ (A). 


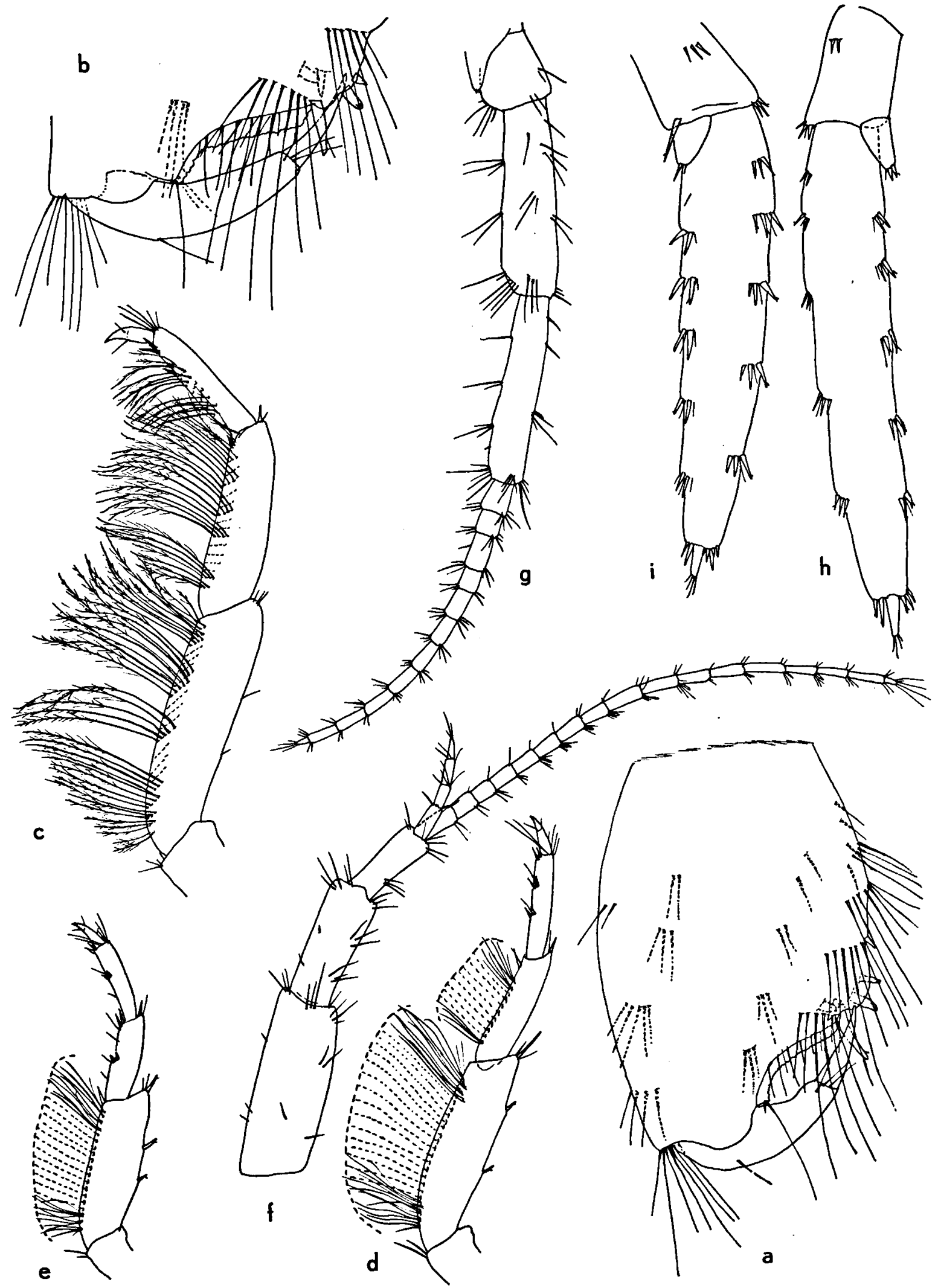

Fig. 19. Rhipidogammarus karamani n.sp., paratypes, coll. ZMA. a, propodus of first leg, of (scale B); b, distal part of propodus of second leg, $\hat{\delta}$ (B); c, third leg, $\hat{\delta}$ (A); d, e, distal part of third leg of two different adult

females (A); $f$, first antenna, $\hat{o}$ (A); $g$, second antenna, $f(A) ; h$, third uropod, of (A); i, third uropod, $\&$ (C). Fine ornamentation of the elements omitted in $a, b, d$, and $e$. 
was selected from a sample collected at Carry-le Rouet (Bouches-du-Rhône, France), in a source a dozen of meters from the mediterranean coast. Both Catta's well and the source at Carry-le Rouet contained brackish water.

The neotype is preserved in the Zoölogisch Museum, Amsterdam, cat. no. Amph. 102.979.

Rhipidogammarus karamani n. sp. Figs. 1 e, k, 1; 19.

Neogammarus rhipidiophorus (non Catta), - S. Karaman, $195 \overline{50}$ (pro parte, only the Yugoslavian record): 175-186, figs. 1-2, 4-14; G. Karaman, ?1969c: 47-58 (pro parte, only the Yugoslavian records).

Gammarus (Neogammarus) rhipidiophorus (non Catta). - Ruffo, 1960: 176 (pro parte, Corfu record only).

Material examined. -

France, Corsica:

- Nameless stream discharging on the beach near Miomo, Cap Corse. In gravel. Chlorinity $53 \mathrm{mg} / 1.21 \mathrm{Dec}$. 1970. 81 \&, 4 of (1 of holotype, the rest paratypes); (ZMA Amph. 102.978).

- Nameless stream discharging on gravel of the beach near Lavasina, Cap Corse. Chlorinity $28 \mathrm{mg} / \mathrm{l}$ (but during stormy weather within reach of the waves). 21 Dec. 1970. 4 ô, 1 \& (ZMA).

Greece:

- Pirgy, northeast coast of the island of Corfu, in débris of Posidonia, in a marine erosion cave. 25 Apr. 1957, 6 of $(\mathrm{MCV})$.

Other records. - Various localities in Yugoslavia ( $\mathbf{S}$. Karaman, 1950; G. Karaman, 21969c).

Description. - Male: Maximum length about 8 $\mathrm{mm}$. Very similar to $R h$. rhipidiophorus, but differing in the A1, A2, and Ur. 3.

The first antenna (fig. 19f) has shorter setae on the ventral margin of peduncle segments 2 and 3 (in rhipidiophorus: setae as long as, or longer than the diameter of the segment; in karamani: setae shorter than the diameter of the segment).

The second antenna (fig. 19g) bears the same number of groups of setae on the inferior margin of peduncle segments 4 and 5 as in rhipidiophorus, but whereas in the latter the setae are long and the groups are separated by small intervals, are the setae in karamani markedly shorter (about the diameter of the segment), and are the groups of setae separated by intervals that are wider than the length of the setae. The flagellum bears setae that are shorter than the diameter of the flagellar articles (in rhipidiophorus at least some of the setae are much longer than this diameter).

The third uropod (fig 19h) has an elongated first exopod segment, armed with groups of short spines on its lateral and medial margins. In each group of spines, usually a short setule (of about the length of the spines) is found. In rhipidiophorus, numerous setae are intermixed with the spines, and these setae are 2 to 4 times as long as the spines. The medial margin of the first exopod segment in karamani is provided with spines of reduced length. In a number of specimens of both sexes, the length of the spine was measured and expressed as a function of the exopodal diameter (see fig. 20 for the way the measurements have been taken). The ratio $\mathrm{A} / \mathrm{B}$ (= exopodal diameter/spine length) was $3.2-3.4$ in karamani, $2.1-2.4$ in rhipidiophorus. The second exopod segment is narrow, tapering, and distally armed with

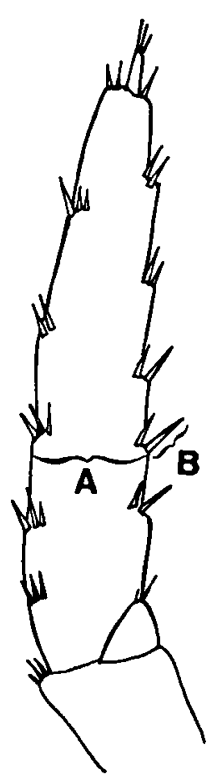

Fig. 20. The relative length of the spines on the medial margin of the first exopod segment in the third uropod ( $\hat{\sigma} q$ ) is distinctive for Rhipidogammarus rhipidiophorus and $R h$. karamani. In the text, the ratio A/B (diameter uropod/length spine) is used as parameter.

very short setae (shorter than the length of the segment), whereas these setae are longer than the segment in rhipidiophorus.

Female: Same maximum size as the male. In this sex $R h$. karamani is hard to distinguish from $R h$. rhipidiophorus.

The distal seta of the third peduncle segment of $\mathrm{Al}$ is shorter than in rhipidiophorus. The setae on the flagellum of A2 are, just as in male, dis- 


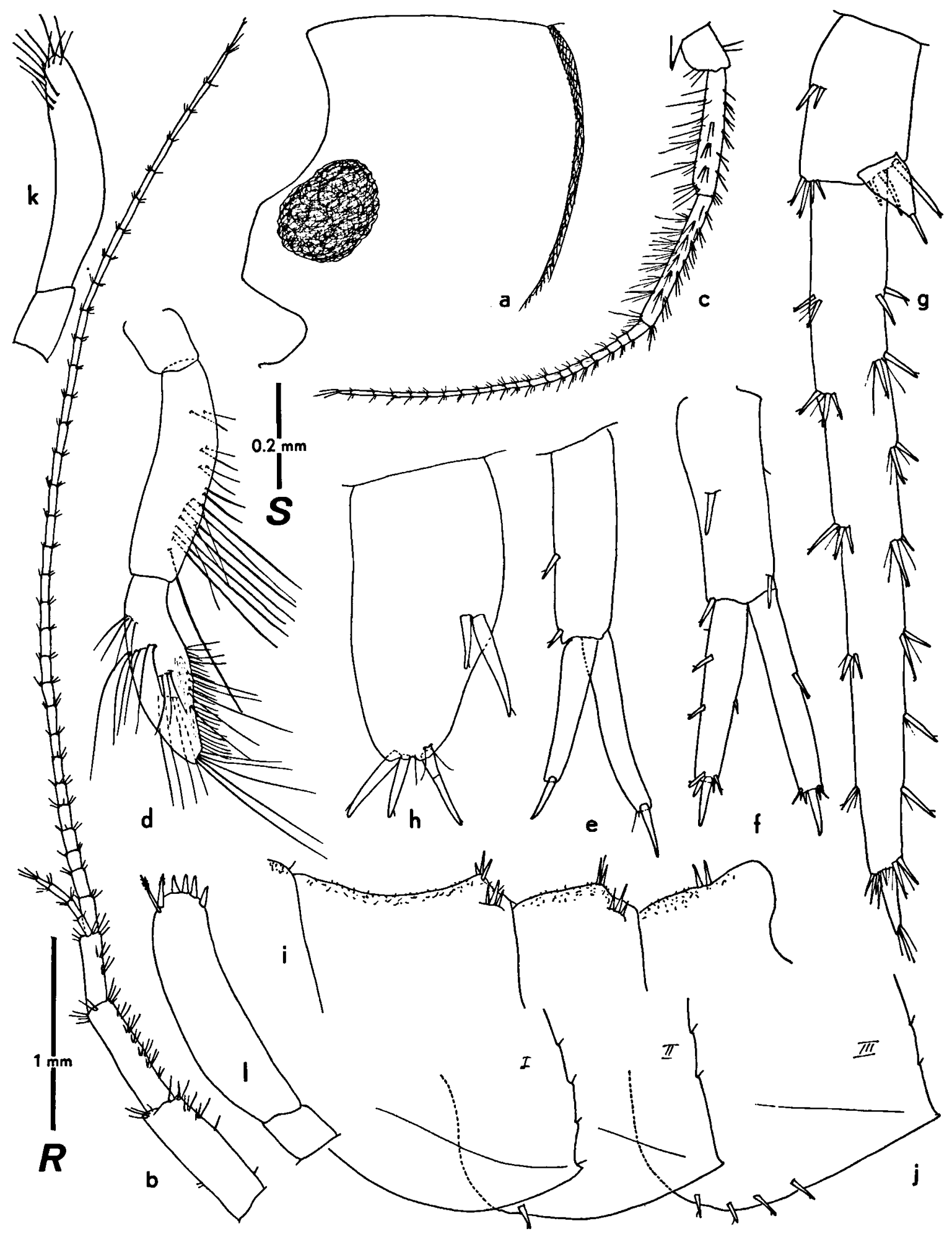

Fig. 21. Longigammarus bruni (G. Karaman, 1969), from Bouches-du-Loup, France, coll. ZMA. a, head from the left, $\hat{o}$ (scale C); b, first antenna, $\hat{o}(\mathrm{R})$; c, second antenna, $\hat{\delta}(\mathrm{R})$; $\mathrm{d}$, mandible palp, fine ornamentation of the elements omitted, $\delta(S)$; e, first uropod, $\delta(G)$; $f$, second uropod, $\hat{\sigma}(\mathrm{G})$; $\mathrm{g}$, third uropod, $\delta(\mathrm{G})$; $\mathrm{h}$, right telson lobe, $\hat{\delta}(\mathrm{B})$; $\mathrm{i}$, dorsal contour of urosome, $\hat{\delta}(\mathrm{A})$; j, epimeral plates I, II, and III, from the left, of (C); $k$, palp of left first maxilla, $\$$ (B); 1 , palp of right first maxilla, \& (B). 

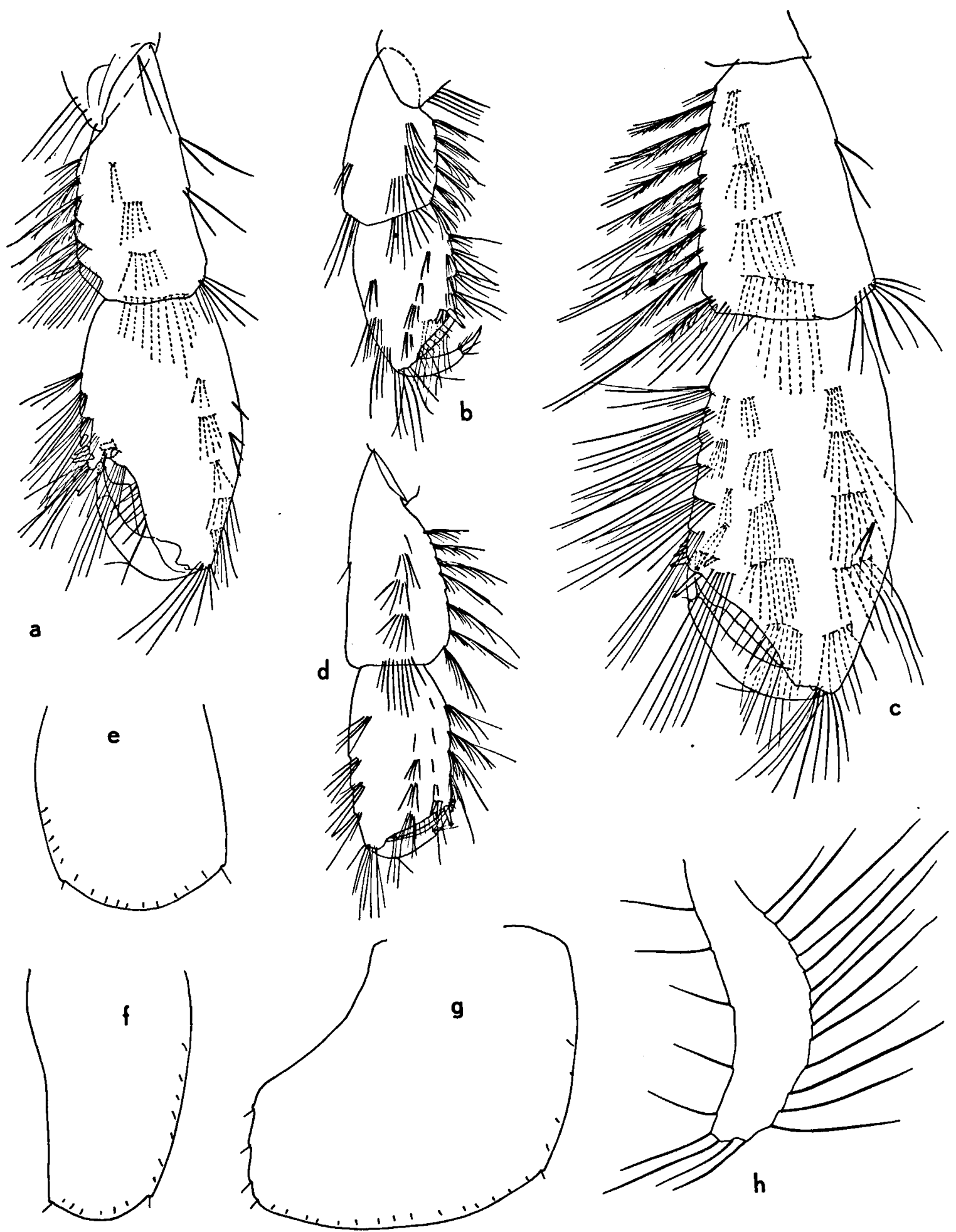

Fig. 22. Longigammarus bruni (G. Karaman, 1969), from Bouches-du-Loup, France, coll. ZMA. a, distal portion of leg 1, of (O); b, distal portion of leg 1, \& (C); $c$, distal portion of leg $2, \delta(O)$; d, distal portion of leg 2 ,

\& (C); e, first coxal plate, $\delta$ (G); f, second coxal plate, of (G); $g$, fourth coxal plate, of (G); h, incubatory lamella of leg $2, q$ (A). Fine ornamentation of the elements omitted in $a, b, c$, and $d$. 
tinctive. The third uropod in females of rhipidiophorus is less hairy than in males, so the distinction based on the length and number of the setae is less marked, although still visible (fig. 15i). The characteristic short spines on the medial margin of the first exopod segment of Ur. 3 are present in female as in male.

Colour in life: pale; eye black.

Remarks. - S. Karaman, 1950, was the first to emphasize that certain populations of $R h$. rhipidiophorus had hairy, while others had spiny third uropods. He refrained from evaluating these features, since he did not have access to topotypical material. G. Karaman, ?1969c, noticed the same feature in populations from Yugoslavia and from Nice.

Although the two uropod types ("spiny" and "hairy") are correlated with other differences (viz., in the setation of $\mathrm{A} 1$ and $\mathrm{A} 2$, the "spiny" form bearing shorter setae), the suspicion that age stages of one species are concerned seems justified, in particular since it is known that the setation in Gammaridae increases with age. In the Rhipidogammarus material, no confirmation for this suspicion was found. The largest (oldest) males had, just as the smallest (youngest) males, spiny uropods.

In specimens of an average size, both the spiny and hairy types were found. It was assumed, therefore, that the larger spiny individuals represented a species different from the hairy ones, and that the smaller spiny individuals represented an undifferentiated juvenile stage that could develop either into the hairy or into the spiny type.

This assumption is corroborated by the following observations:

(1) In some estuarine Corsican localities, both types live intermixed, but they retain their morphological individuality.

(2) In most localities, especially in those more or less strongly influenced by fresh water, only the hairy type exists.

(3) The characters in uropods and antennae are constantly present throughout the range of both forms (hairy form: almost circum-mediterranean; spiny form: northern belt of mediterranean basin from Corsica to Greece).

(4) Differences of the degree as found here, often are of specific importance in sibling species of gammarids, compare e.g. the distinction between Gammarus zaddachi and G. salinus.
It must be admitted that no interbreeding experiments have so far been carried out. But the fact that both forms can occur together, without forming intermediates, is an indication that no seasonal morphs, ecophenotypes or subspecies are involved.

The new species is dedicated to Drs. Stanko and Gordan S. Karaman, father and son, who have first noticed the differences in the uropods, and in recognition of their numerous other fine studies on amphipods.

Longigammarus G. Karaman, 1969 (new rank)

Neogammarus (Longigammarus) G. Karaman 21969c: 50, 57; G. Karaman, 1970: 52.

Diagnosis. - Gammaridae, Sarathrogammarusgroup. Eyes pigmented (small and rounded in the single species known). Dorsal surface of urosome provided with spines. A2 $\sigma^{*}$ without calceoli. Mouth parts $\left(\sigma^{*} \%\right)$ modified (lobes of mxl, in particular the outer one, widened; all spines on outer lobe of $\mathrm{mx} 2$ provided with 20-30 unilateral teeth; inner lobe of mxp widened; outer lobe of mxp with setiform elements only). P3 ( $\left.\sigma^{\prime} \%\right)$ modified. P5 to P7 ( $\left.\sigma^{*} q\right)$ slender. Uropod 1 ( $\left.\sigma^{*} q\right)$ reduced. Uropod $3\left(\sigma^{n} q\right)$ with reductions in 2 nd exopod segment and in endopod.

Type species by monotypy: Neogammarus (Longigammarus) bruni G. Karaman, ?1969c.

Remarks. - This taxon was cited twice by $\mathbf{G}$. Karaman (?1969c; 1970), and vaguely diagnosed. Although reference is made (in Karaman, ?1969 c) to a paper in Fragmenta Balcanica, 1969, in which the formal description of $N$. (L.) bruni had to be appear, this fascicule apparently has not yet been published at this moment (= July 1971). Formally, therefore, the type species, $N$. (L.) bruni is a nomen nudum, but since $I$ have numerous specimens of both sexes at my disposal from the type locality, which conform in all details the scanty key characters mentioned in Karaman's papers, I have no hesitation to introduce the taxon under the name proposed by Karaman in this revision.

Since the mouth parts in all members of the Sarathrogammarus-group studied are pretty much the same, the present species, with its aberrant mouth parts stands well apart, and is treated here as a full genus, and certainly not as a subgenus of Neogammarus, a genus with which it has - at least not in the conception of Neogammarus used in this paper - not much in common. 


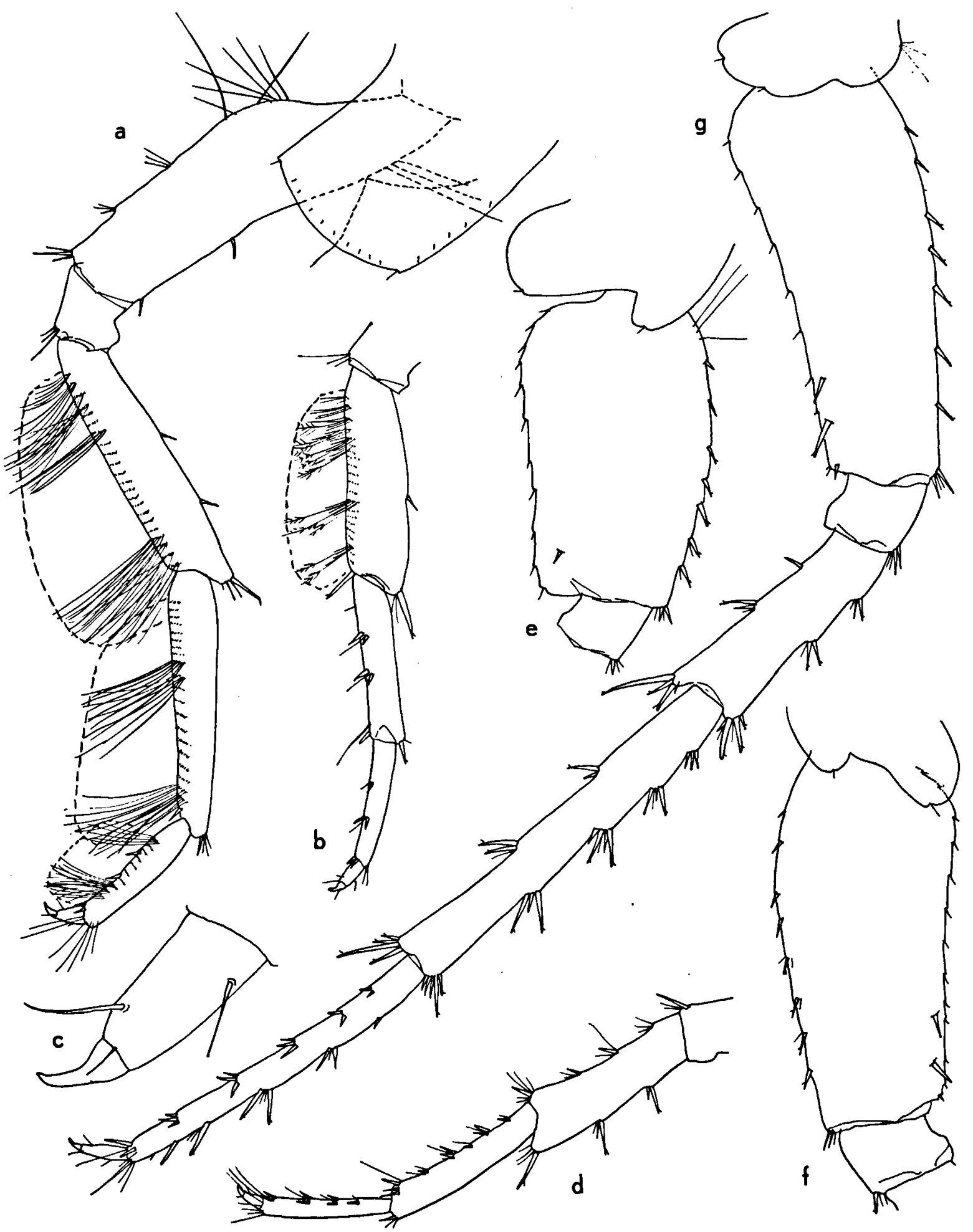

Fig. 23. Longigammarus bruni (G. Karaman, 1969), from Bouches-du-Loup, France, coll. ZMA. a, third leg, of (M) (fine ornamentation of elements omitted); b, distal portion of third leg, $f(A)$; c, claw of third leg, of (N); d, distal portion of fourth leg, of (M); e, proximal portion of fifth leg, $\delta(M)$; $f$, proximal portion of sixth leg, ô $(\mathrm{M}) ; \mathrm{g}$, seventh leg, ô $(\mathrm{M})$. 
Longigammarus bruni (G.Karaman, 1969). Figs. 1 a, c, o; 21; 22; 23.

Neogammarus (Longigammarus) bruni G. Karaman, 21969c: 50, 52, 57; G. Karaman, 1970: 52.

Material examined. -

France:

- Dép. Alpes-Maritimes: mouth of river Loup, at Bouches-du-Loup, near the place where the river streams over the beach into the sea, in gravel, depth 10 to $100 \mathrm{~cm}$, several dates in July 1971, many specimens, of both sexes, incl. ovigerous females (ZMA), chlorinity $32-37 \mathrm{mg} / \mathrm{l}$.

This is topotypic material, since G. Karaman (1970: 52) mentions "iz Francuske (ušce rijeke Loup)" as type locality.

Remarks. - This interesting form bears quite rightly the name Longigammarus, because several appendages, in particular A1, P1 to P7, and ur3, are extremely elongated. A set of figures based on a topotypic male (length $91 / 2 \mathrm{~mm}$ ) and female (length $8 \mathrm{~mm}$ ) is incorporated in this paper. But for the aberrant mouth parts, $L$. bruni appears to be most closely related to Rhipidogammarus.

$L$. bruni is the predominant amphipod in gravel of the mouth of the river Loup, W. of Nice, France, in a narrow zone on the beach where the river water mixes with the waves. It is accompanied in the fresher part of its range by Echinogammarus fluminensis Pinkster \& Stock, in the mixohaline part of its range by Echinogammarus foxi (Schellenberg) and. Rhipidogammarus rhipidiophorus (Catta) (in this mixohaline part of the river Longigammarus reaches its optimal occurrence), and in the most saline part of its range by Neogammarus nudus Stock and Rhipidogammarus rhipidiophorus.

Longigammarus bruni moves in a somewhat worm-like, or better Niphargus-like, way. The body is pale grayish to yellowish, the intestine is orangebrown to dark gray, the eye is black, and the eggs are blackish.

\section{REFERENCES}

BARNARD, J. L., 1958. Index to the families, genera and species of the gammaridean Amphipoda (Crustacea) Occ. Pap. Allan Hancock Found., $19: 1-145$.

BERNER, L., 1966. Note sur Gammarus rhipidiophorus Catta 1878. Arch. Hydrobiol., 61 (4) : 471-475.

Birstein, J. A., 1948. (Amphipoda of Tadzjikistan). Prof. Zernov Memorial Volume: 263-273 (in Russian).

CatTA, J.-D., 1878. Sur un Amphipode nouveau, le Gammarus Rhipidiophorus. Actes Soc. helv. Sci. nat. Bex, 60 : $256-263$.

Chevreux, E., 1889. Quatrième campagne de l'Hirondelle, 1888. Description d'un Gammarus nouveau, des eaux douces de Florès. Bull. Soc. zool. France, 14 : $294-296$.

- 1900. Amphipodes provenant des campagnes de l'Hirondelle. Rés. Camp. sci. Albert I Monaco, 16 : i-iv, 1-195, pls. I-XVIII.

- , 1901. Amphipodes des eaux souterraines de France et d'Algérie. Bull. Soc. zool. France, $26: 216-222$.

-, 1910. Campagnes de la Melita. Les Amphipodes d'Algérie et de Tunisie. Mém. Soc. zool. France, 23 : 145-285, pls. VI-XX.

Chevreux, E. \& L. Fage, 1925. Amphipodes. Faune de France, $9: 1-488$.

Chevreux, E. \& J. De Guerne, 1892. Description de Gammarus Delebecquei nov. sp. du Lac d'Annecy, suivie de quelques remarques sur les Amphipodes d'eau douce de la France. Bull. Soc. zool. France, 17 : $136-142$.

DAHL, E., 1958. Fresh and brackish water amphipods from the Azores and Madeira. Boletim Mus. munic. Funchal, 11 (27) : 5-25.

-, 1959. Intertidal ecology in the terms of poikilohalinity. Archivio Oceanogr. Limnol., 11 (Suppl.) : 225237.

Gauthier, H., 1936. Eriopisa seutati, nouvel Amphipode du Sud-tunisien. Bull. Soc. Hist. nat. Afr. Nord, 27 : $133-143$.

Karaman, G. S., 1969a. XXII. Beitrag zur Kenntnis der Amphipoden. Ueber einige neue Formen des Genus Sarathrogammarus (Gammaridae) aus Afghanistan. Acta Mus. macedon. Sci. nat., 11 (11) : 195-208.

-, ?1969b. XXIII. Beitrag zur Kenntnis der Amphipoden. Die Gattung Sarathrogammarus Mart. in Asien. Glasnik Republ. Zavoda Zaštitu Prirode Prirodnjačke Zbirke Titogradu, 2 : 33-45,

-, ?1969c. XXVI. Beitrag zur Kenntnis der Amphipoden. Taxonomie und Verbreitung der Art Neogammarus rhipidiophorus (Catta) in Mittelmeerbassin. Glasnik Republ. Zavoda Zaštitu Prirode Prirodnjačke Zbirke Titogradu, $2: 47-58$, pls. I-IV.

-, 1970. XXV. Beitrag zur Kenntnis der Amphipoden. Kritische Bemerkungen über Echinogammarus acarinatus (S. Kar. 1931) und Echinogamm. stocki n. sp. Poljoprivreda i šumarstvo Titograd, 16 (1-2): 45- 46 , pls. I-V.

-, 1971. XIX. Beitrag zur Kenntnis der Amphipoden. Eine neue Art der Gattung Sarathrogammarus (Gammaridae) aus Afghanistan, S. ruffoi n. sp. Crustaceana, 20 (2) : 199-207. 
Karaman, S., 1931. III. Beitrag zur Kenntnis der Amphipoden Jugoslaviens, sowie einiger Arten aus Griechenland. Prirodoslovne Razprave, 1: 31-66.

- , 1950. Neogammarus rhipidiophorus Catta aus unterirdischen Gewässern der Adriatischen Küste. Monogr. Acad. Serbe Sci., Sect. Sci. math. nat., (n.S.) 2 : $175-186$.

Martynov, A., 1935. Amphipoda Gammaridea of the running waters of Turkestan. Trav. Inst. zool. Acad. Sci. URSS, 2 : 411-508.

Martynov, A. W. \& A. L. Behning, 1948. (Some centralasiatic gammarids). Trudy zool. Inst. Akad. Nauk SSSR, 7 : 171-176 (in Russian).

Pacaud, A., 1952. Nouvelle revue de la distribution géographique des Gammares dans les eaux continentales françaises. C.R. Soc. biogéogr., 252/253 : 95111.

Pinkster, S, 1969. A new Echinogammarus of the berilloni-group, E. aquilifer nov. sp., from the Pyrenees (Crustacea, Amphipoda). Bull. zool. Mus. Univ. Amsterdam, 1 (11) : 137-142.

Pinkster, S. \& J. H. Stock, 1970. Western European species of the presumed Baikal-genus Eulimnogammarus (Crustacea-Amphipoda), with description of a new species from Spain. Bull. zool. Mus. Univ. Amsterdam, 1 (14) : 205-219.

Rufro, S., 1937. Studi sui Crostacei Anfipodi, 5. Una nuova specie di Gammarus del mar Ligure. Annali Mus. civ. Stor. nat. Giacoma Doria, 59: 438-446.

-, 1939. Studi sui Crostacei Anfipodi, 7. Osservazioni sopra alcuni Gammaridi nord-africani. Atti Soc. Ital. Sci. nat. Mus. civ. Stor. nat. Milano, 78 : 55-62.

-, 1951. Rinvenimento di Gammarus (Neogammarus) rhipidiophorus Catta nelle acque sotterranee della Liguria. Doriana, 1 (18) : 1-4.
-, 1958. Due nuove specie di Anfipodi delle acque sotterranee dell'Afghanistan. Memorie Mus. civ. Stor. nat. Verona, $6: 389-403$.

- , 1960. Contributo alla conoscenza dei Crostacei Anfipodi delle acque sotterranee della Sardegna e della Baleari. Atti Inst. Veneto Sci. Lett. Arti, 118 (Cl. Sci. mat. nat.) : 169-180.

Schellenberg, A., 1937. Schlüssel und Diagnosen der dem Süsswasser-Gammarus nahestehenden Einheiten ausschliesslich der Arten des Baikalsees und Australien. Zool. Anz., 117 (1-2) : 267-280.

Sexton, E. W. \& G. M. Spooner, 1940. An account of Marinogammarus (Schellenberg) nov. gen. (Amphipoda), with a description of a new species $M$. pirloti. J. mar. biol. Ass. U.K., 24 : 633-682, 1 pl.

SkET, B., 1969. Ueber die Verbreitung einiger Malacostraca (Hadzia, Salentinella, Neogammarus, Jaera) längs der Jugoslawischen Adria-Küste. Bull. sci., (A) 14 (5-6) : 147-148.

Stebbing, T. R. R., 1888. Report on the Amphipoda collected by $H$. M. S. Challenger during the years 1873-1876. Rep. sci. Res. Challenger, (Zool.) 29 (in 3 pts.) : i-xxiv, 1-1737, pls. I-CCX.

-, 1906. Amphipoda, 1. Gammaridea. Tierreich, 21 : i-xxxix, 1-806

Stock, J. H., 1967. A revision of the European species of the Gammarus locusta - group (Crustacea, Amphipoda). Zool. Verhand. Leiden, $90: 1-56$.

- , 1968. A revision of the European species of the Echinogammarus pungens - group (Crustacea, Amphipoda). Beaufortia, 16 (211): 13-78.

StrašKraba, M., 1967. Amphipoda, in: J. Illies (ed.), Limnofauna Europaea: 202-209. (Gustav Fischer, Stuttgart). 